\title{
Calibration and measurement uncertainties of a continuous-flow cloud condensation nuclei counter (DMT-CCNC): CCN activation of ammonium sulfate and sodium chloride aerosol particles in theory and experiment
}

\author{
D. Rose ${ }^{1}$, S. S. Gunthe ${ }^{1}$, E. Mikhailov ${ }^{1,2}$, G. P. Frank ${ }^{1, *}$, U. Dusek ${ }^{1, * *}$, M. O. Andreae ${ }^{1}$, and U. Pöschl ${ }^{1}$ \\ ${ }^{1}$ Max Planck Institute for Chemistry, Biogeochemistry Department, P.O. Box 3060, 55020 Mainz, Germany \\ ${ }^{2}$ Atmospheric Physics Department, Institute of Physics, St. Petersburg State University, 198904 St. Petersburg, Russia \\ * now at: Lund University, Department of Physics, Lund, Sweden \\ *** now at: IMAU, Utrecht University, Utrecht, The Netherlands
}

Received: 5 April 2007 - Published in Atmos. Chem. Phys. Discuss.: 14 June 2007

Revised: 18 January 2008 - Accepted: 23 January 2008 - Published: 29 February 2008

\begin{abstract}
Experimental and theoretical uncertainties in the measurement of cloud condensation nuclei $(\mathrm{CCN})$ with a continuous-flow thermal-gradient CCN counter from Droplet Measurement Technologies (DMT-CCNC) have been assessed by model calculations and calibration experiments with ammonium sulfate and sodium chloride aerosol particles in the diameter range of $20-220 \mathrm{~nm}$. Experiments have been performed in the laboratory and during field measurement campaigns, covering a wide range of instrument operating conditions (650-1020 hPa pressure, 293-303 K inlet temperature, $4-34 \mathrm{~K} \mathrm{~m}^{-1}$ temperature gradient, $0.5-1.0 \mathrm{~L} \mathrm{~min}^{-1}$ flow rate). For each set of conditions, the effective water vapor supersaturation $\left(S_{\text {eff }}, 0.05-1.4 \%\right)$ was determined from the measured $\mathrm{CCN}$ activation spectra (dry particle activation diameters) and Köhler model calculations. High measurement precision was achieved under stable laboratory conditions, where the relative standard deviations of $S_{\text {eff }}$ were as low as $\pm 1 \%$. During field measurements, however, the relative deviations increased to about $\pm 5 \%$, which can be mostly attributed to variations of the CCNC column top temperature with ambient temperature. The observed dependence of $S_{\text {eff }}$ on temperature, pressure, and flow rate was compared to the CCNC flow model of Lance et al. (2006). At high $S_{\text {eff }}$ the relative deviations between flow model and experimental results were mostly less than $10 \%$, but at $S_{\text {eff }} \leq 0.1 \%$ they exceeded $40 \%$. Thus, careful experimental calibration is required for high-accuracy CCN measurements - especially
\end{abstract}

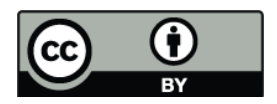

Correspondence to: D. Rose (rose@ mpch-mainz.mpg.de) at low $S_{\text {eff. A comprehensive comparison and uncertainty }}$ analysis of the various Köhler models and thermodynamic parameterizations commonly used in $\mathrm{CCN}$ studies showed that the relative deviations between different approaches are as high as $25 \%$ for $\left(\mathrm{NH}_{4}\right)_{2} \mathrm{SO}_{4}$ and $12 \%$ for $\mathrm{NaCl}$. The deviations were mostly caused by the different parameterizations for the activity of water in aqueous solutions of the two salts. To ensure comparability of results, we suggest that CCN studies should always report exactly which Köhler model equations and parameters were used. Provided that the Aerosol Inorganics Model (AIM) can be regarded as an accurate source of water activity data for highly dilute solutions of $\left(\mathrm{NH}_{4}\right)_{2} \mathrm{SO}_{4}$ and $\mathrm{NaCl}$, only Köhler models that are based on the AIM or yield similar results should be used in CCN studies involving these salts and aiming at high accuracy. Experiments with $\left(\mathrm{NH}_{4}\right)_{2} \mathrm{SO}_{4}$ and $\mathrm{NaCl}$ aerosols showed that the conditions of particle generation and the shape and microstructure of $\mathrm{NaCl}$ particles are critical for their application in $\mathrm{CCN}$ activation experiments (relative deviations up to $18 \%)$.

\section{Introduction}

Aerosol particles serving as cloud condensation nuclei (CCN) play an important role in the formation of clouds and precipitation, and they influence atmospheric chemistry and physics, the hydrological cycle, and climate (Pruppacher and Klett, 1997; Seinfeld and Pandis, 1998; Lohmann and Feichter, 2005). Recent studies indicate that the abundance and properties of $\mathrm{CCN}$ may also affect precipitation amount and

Published by Copernicus Publications on behalf of the European Geosciences Union. 
intensity, heavy weather events and atmospheric dynamics (Andreae et al., 2004; Khain et al., 2005; Rosenfeld and Givati, 2006; Segal and Khain, 2006). The response of cloud characteristics and precipitation processes to increasing anthropogenic aerosol concentrations represents one of the largest uncertainties in the current understanding of climate change (Andreae et al., 2005; IAPSAG, 2007; IPCC, 2007). One of the crucial underlying challenges is to determine the ability of aerosol particles to act as $\mathrm{CCN}$ under relevant atmospheric conditions, an issue that has received increasing attention over the past years (McFiggans et al., 2006; IAPSAG, 2007).

The activation of $\mathrm{CCN}$, i.e., the formation of cloud droplets by the condensation of water vapor on aerosol particles, is determined by particle size and composition as well as water vapor supersaturation (Charlson et al., 2001; Segal et al., 2004; Andreae et al., 2005, 2007; McFiggans et al., 2006).

Reliable measurement data of atmospheric $\mathrm{CCN}$ concentration and size distribution as a function of water vapor supersaturation are required for the quantitative description, understanding, and assessment of the effects of natural background aerosols and anthropogenic pollution on the atmosphere and climate. Therefore, CCN measurements have been performed in laboratory and field experiments around the globe, and more are under way (e.g., Gras, 1995; Hudson and Xie, 1999; Delene and Deshler, 2001; Giebl et al., 2002; Hudson and Yum, 2002; Raymond and Pandis, 2003; Bilde and Svenningsson, 2004; Broekhuizen et al., 2004, 2006; Henning et al., 2005; Dusek et al., 2006; Reade et al., 2006; Roberts et al., 2006; Dinar et al., 2006; Wex et al., 2006; Ervens et al., 2007; Rissman et al., 2007).

Instruments that measure $\mathrm{CCN}$ concentrations at prescribed water vapor supersaturations have been available and in use for decades, but the reliability of the measurement results has been a subject of continuing debate (e.g., Hudson, 1989, 1993; Chuang et al., 2000; Delene and Deshler, 2000; Snider et al., 2003, 2006; Chan and Chan, 2005; Wex et al., 2005; McFiggans et al., 2006).

Only recently has an instrument promising enhanced robustness and reliability become commercially available: the continuous-flow streamwise thermal-gradient cloud condensation nuclei counter (CCNC) from Droplet Measurement Technologies (DMT). The design and operating principles of the instrument are based on Roberts and Nenes (2005) as detailed below. Numerous atmospheric research groups around the world have recently begun to use instruments of this type for $\mathrm{CCN}$ field and laboratory studies (e.g., Kuwata et al., 2007a, b; Padró et al., 2007; Petters et al., 2007; Yum et al., 2007; Shilling et al., 2007; Engelhart et al., 2008).

In this study, we describe how the DMT-CCNC can be efficiently calibrated by experiments using salt aerosol particles of known size and composition, and the corresponding Köhler model calculations (Sect. 2, Appendix A). We investigate and quantify the variability and uncertainty of mea- surements and data analysis (Sects. 3.1-3.4), and we test the applicability of a CCNC flow model by Lance et al. (2006) for extrapolating DMT-CCNC calibration results to different measurement conditions (temperature, pressure, flow rate; Sects. 3.5 and 3.6). Moreover, we characterize the deviations between different Köhler modeling approaches (Sect. 3.7), and we compare experimental and model results for ammonium sulfate and sodium chloride, addressing the influence of aerosol generation and particle shape (Sect. 3.8).

\section{Methods}

\subsection{Cloud condensation nuclei counter (CCNC)}

The CCNC used and characterized in this study is a continuous-flow streamwise thermal-gradient $\mathrm{CCN}$ counter, commercially available from Droplet Measurement Technologies, Inc. (DMT, model No. CCN-2, serial number 02/05/0011). The design and operating principles of the instrument are based on Roberts and Nenes (2005). The core of the DMT-CCNC is a vertical flow tube of cylindrical shape (inner diameter $2.3 \mathrm{~cm}$, length $50 \mathrm{~cm}$ ), in which the aerosol sample, surrounded by filtered sheath air (total flow rate $Q=0.5-1 \mathrm{~L} \mathrm{~min}^{-1}$, sheath-to-aerosol flow ratio 10 ), flows from top to bottom under laminar conditions and nearambient pressure $p$. The porous inner surface of the flow tube is continuously wetted with liquid water from a peristaltic pump. In this study, the pump was generally operated at a water drip rate of $4 \mathrm{~mL} \mathrm{~h}^{-1}$ corresponding to the CCNC software setting of "low" liquid flow. In the CCNC, a near-linear positive temperature gradient along the flow direction is established and controlled by thermal electric coolers (TEC) and thermocouples, which are mounted at the beginning, middle, and end of the outer wall of the tube (temperatures $T_{1}, T_{2}$, and $T_{3}$, respectively). As the laminar flow passes through the column, heat and water vapor are transported from the inner surface towards the center of the tube. Because water molecules diffuse more quickly than heat, a constant water vapor supersaturation is established along the centerline of the column.

The aerosol sample enters the column at the top center of the column, and particles with a critical supersaturation less than the centerline supersaturation are activated as $\mathrm{CCN}$ (for definitions of supersaturation and critical supersaturation see Sect. 2.3). The residence time in the column $(\sim 6-12 \mathrm{~s}$, depending on flow rate) enables the activated particles to grow into droplets that are sufficiently large $(>1 \mu \mathrm{m})$ to be detected separately from unactivated particles (usually $\ll 1 \mu \mathrm{m}$ ). An optical particle counter (OPC) at the exit of the column determines the concentration and size distribution of droplets in the size range of $0.75-10 \mu \mathrm{m}$. Droplets larger than $1 \mu \mathrm{m}$ are considered to be activated CCN.

The effective water vapor supersaturation $\left(S_{\text {eff }}\right)$ in the CCNC is determined by flow rate, pressure, sample 
temperature and temperature gradient. The temperature gradient is controlled by the temperature difference $\left(\Delta T=T_{3}-\right.$ $\left.T_{1}\right)$ between the top $\left(T_{1}\right.$, set $\sim 3 \mathrm{~K}$ higher than the sample temperature) and the heated bottom of the column $\left(T_{3}\right.$, maximum $\sim 325 \mathrm{~K}$, limited by OPC operating conditions). The CCNC operating software automatically keeps $T_{2}$ slightly higher than it would have to be for a perfectly linear gradient $(\sim 1 \%)$. This results in a slightly higher temperature gradient in the first half and smaller temperature gradient in the second half of the flow column, which helps to restrict the actual CCN activation of aerosol particles to the first half of the column and to ensure sufficient time for droplet growth in the second half of the column. In this study, $\Delta T$ and $S_{\text {eff }}$ have been varied in the range of $2-17 \mathrm{~K}$ (corresponding to gradients of $4-34 \mathrm{~K} \mathrm{~m}^{-1}$ ) and $0.05-1.3 \%$, respectively. Shifting from one supersaturation level to another requires approximately $0.5-3.5 \mathrm{~min}$, depending on the size of the step, and whether it is from lower to higher supersaturations (shorter time) or vice versa (longer time).

\subsection{Experimental setup and aerosol generation}

The calibration setup used in this study was similar to the one described by Frank et al. (2007), and is illustrated in Fig. 1. Calibration aerosol was generated by nebulization of an aqueous salt solution (solute mass concentration $\sim 0.01 \%$ ) of ammonium sulfate $\left(\left(\mathrm{NH}_{4}\right)_{2} \mathrm{SO}_{4}\right.$, purity $>99.5 \%$, supplier: E. Merck, Darmstadt) or sodium chloride (NaCl, purity $>99.99 \%$, supplier: Alfa Aesar GmbH \& Co KG), using a TSI 3076 Constant Output Atomizer operated with particle-free pressurized air $\left(2.5 \mathrm{bar}, 2 \mathrm{~L} \mathrm{~min}^{-1}\right)$. The polydisperse aerosol was dried to a relative humidity of $<15 \%$ by dilution with particle-free dry air $\left(\sim 30 \mathrm{~L} \mathrm{~min}^{-1}\right)$. The excess flow was vented through a filter (HEPA) or into a fume hood/exhaust line, where care was taken to keep overpressure in the system as low as possible (mostly $<20 \mathrm{hPa}$ ). The dry aerosol $\left(0.5-2 \mathrm{~L} \mathrm{~min}^{-1}\right)$ was passed through a bipolar charger/radioactive neutralizer (Ni-63, $555 \mathrm{MBq}$ ) to establish charge equilibrium, and a differential mobility analyzer (DMA; TSI 3071 Electrostatic Classifier) with closed loop sheath air flow $\left(10 \mathrm{~L} \mathrm{~min}^{-1}\right)$ was used to select monodisperse particles. To adjust the particle number concentration, the monodisperse aerosol was diluted with particle free air $(0$ $1 \mathrm{~L} \mathrm{~min}^{-1}$ ) in a small mixing chamber (glass, $\sim 10 \mathrm{~cm}^{3}$, built in-house) at the DMA outlet. After dilution, the monodisperse aerosol flow was split into two parallel lines and fed into a condensation particle counter (CPC; TSI 3762; $\left.1 \mathrm{~L} \mathrm{~min}^{-1}\right)$ and into the CCNC $\left(0.5-1 \mathrm{~L} \mathrm{~min}^{-1}\right)$. For the calibration experiments, the number concentration of monodisperse aerosol particles was kept below $\sim 3 \times 10^{3} \mathrm{~cm}^{-3}$ to avoid counting errors caused by coincidence.

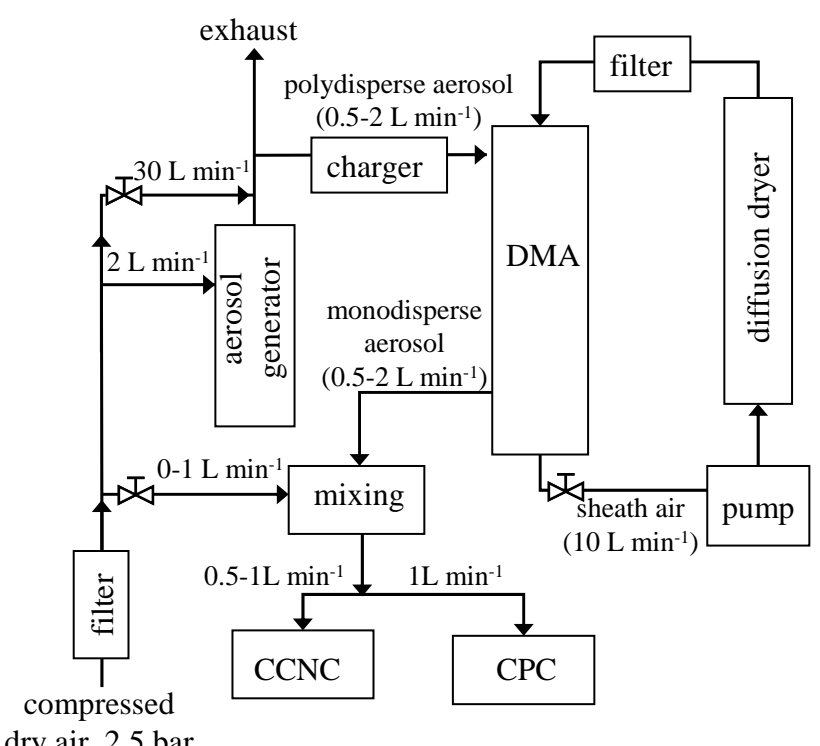

dry air, 2.5 bar

Fig. 1. Experimental setup: DMA - differential mobility analyzer, CCNC - cloud condensation nuclei counter, CPC - condensation particle counter.

\subsection{Calibration experiments and data analysis}

\subsubsection{CCN efficiency spectra and activation diameters $D_{a}$}

\subsubsection{Measurement and fitting procedure}

In every calibration experiment, the $\mathrm{CCNC}$ was operated at five different $\Delta T$ values in the range of $2-17 \mathrm{~K}$. For each $\Delta T$, the diameter of the dry salt aerosol particles selected by the DMA $(D)$ was set to 15 different values in the range of $18-220 \mathrm{~nm}$. At each $D$, the number concentration of total aerosol particles (condensation nuclei, $\mathrm{CN}$ ), $N_{\mathrm{CN}}$, was measured with the CPC, and the number concentration of CCN, $N_{\mathrm{CCN}}$, was measured with the CCNC ( $\sim 60 \mathrm{~s}$ waiting time to adjust to the new particle concentration plus $20-30 \mathrm{~s}$ averaging time). The activated particle fraction, or $\mathrm{CCN}$ efficiency $\left(N_{\mathrm{CCN}} / N_{\mathrm{CN}}\right)$, was calculated from the averaged concentrations of $\mathrm{CN}$ and $\mathrm{CCN}$, and a CCN efficiency spectrum of $N_{\mathrm{CCN}} / N_{\mathrm{CN}}$ over $D$ was obtained from every scan of particle diameters at constant $\Delta T$. In each calibration experiment, multiple scans over $\Delta T$ and $D$ were performed, and multiple CCN efficiency spectra (at least 2, up to 20) were recorded for each $\Delta T$.

Each CCN efficiency spectrum was fitted with a cumulative Gaussian (normal) distribution function using a nonlinear least-squares fitting routine (Gauss-Newton method, Matlab, MathWorks, Inc.):

$$
f_{N_{\mathrm{CCN}} / N_{\mathrm{CN}}}=a\left(1+\operatorname{erf}\left(\frac{D-D_{a}}{\sigma \sqrt{2}}\right)\right)
$$



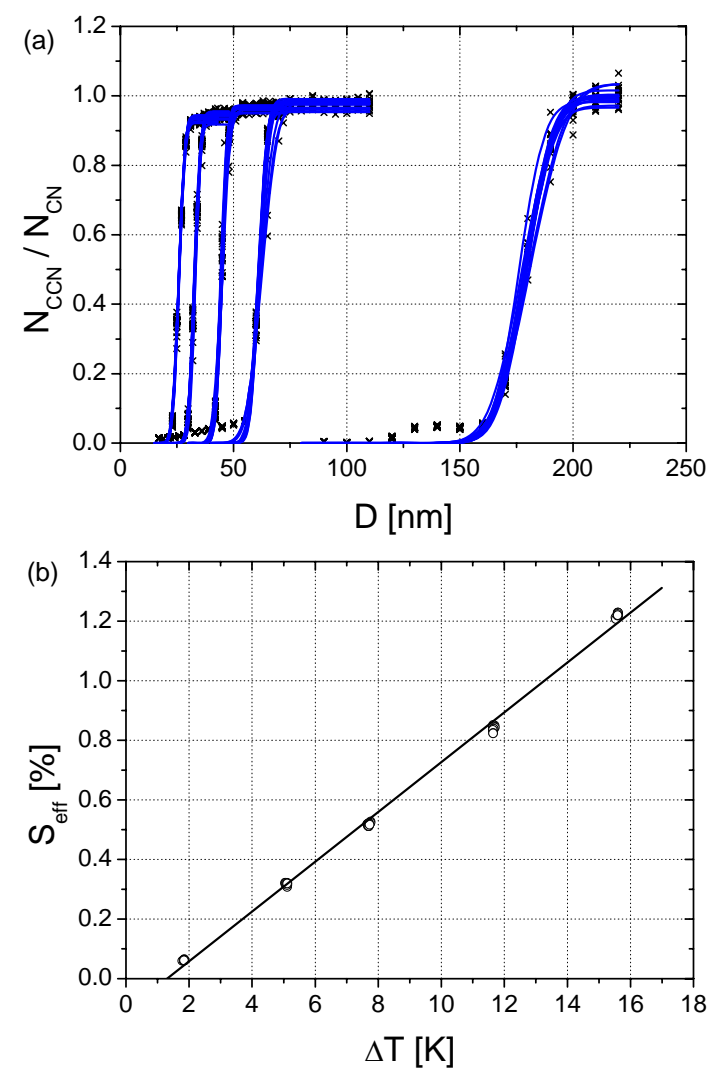

Fig. 2. Exemplary results of a laboratory calibration experiment with ammonium sulfate aerosol (Mainz, 21 December 2005, $\left.Q=0.5 \mathrm{~L} \mathrm{~min}^{-1}, p=1026 \mathrm{hPa}, T_{1}=298.5 \mathrm{~K}\right)$ : CCN efficiency spectra measured at 5 different $\Delta T$ values (a) and the corresponding calibration line (b). The symbols are measurement data points and the solid lines are the cumulative Gaussian distribution (a) and linear fit (b) curves.

where erf is the error function, $a$ is half the maximum value of $f_{N_{\mathrm{CCN}} / N_{\mathrm{CN}}}, D_{a}$ is the particle diameter at $f_{N_{\mathrm{CCN}} / N_{\mathrm{CN}}}=a$, and $\sigma$ is the standard deviation of the cumulative Gaussian distribution function. Ideally, $a$ should equal 0.5 for internally mixed aerosols. As can be seen from exemplary $\mathrm{CCN}$ efficiency spectra illustrated in Fig. 2a, however, deviations from this value can occur due to different particle losses and counting efficiencies of the CPC and CCNC. These deviations can be corrected by normalizing the maximum value of the $\mathrm{CCN}$ efficiency spectrum to unity, i.e., by multiplying the observed values of $N_{\mathrm{CCN}} / N_{\mathrm{CN}}$ with $0.5 / a$. Since the normalization is symmetric with regard to the midpoint of the CCN efficiency spectrum, however, it does not affect the value of $D_{a}$ (Rose et al., 2007).

\subsubsection{Correction for doubly charged particles}

When the DMA selects particles of a given electrical mobility, the particles are not all singly charged. There are also multiply (mostly doubly) charged particles that have the same electrical mobility, but which are larger in diameter. Since the probability of three charges or more is rather low, only doubly charged particles will be mentioned here. Because of their larger diameter, the doubly charged particles activate at a lower supersaturation than the singly charged particles of the same electrical mobility. Therefore, doubly charged particles appear in the $\mathrm{CCN}$ efficiency spectrum $\left(N_{\mathrm{CCN}} / N_{\mathrm{CN}}\right.$ vs. $\left.D\right)$ of a chemically homogeneous aerosol as a plateau at smaller diameters (see Figs. 2a and 3 ). The height of this plateau corresponds to the number fraction of doubly charged particles. It usually increases for larger particle sizes (smaller supersaturations), because the probability of double charging increases (Wiedensohler, 1988). Furthermore, the height of this plateau depends on the shape of the number size distribution of the polydisperse calibration aerosol. The broader the size distribution is, the higher is the concentration of large particles, and the higher is the fraction of doubly charged particles selected by the DMA. High fractions of activated doubly charged particles can distort the CCN efficiency spectra and the derived $D_{a}$ values. This effect can be corrected by calculating the abundance of doubly charged particles from the number size distribution of the polydisperse calibration aerosol assuming a bipolar equilibrium charge distribution and then subtracting them from $N_{\mathrm{CCN}} / N_{\mathrm{CN}}$ as described in Frank et al. (2006).

An alternative method is to fit the sum of two cumulative Gaussian distribution functions to the measured CCN efficiency spectrum. This method yields 6 fit parameters defined in analogy to Eq. (1) $\left(a_{1}, a_{2}, \sigma_{1}, \sigma_{2}, D_{a, 1}, D_{a, 2}\right)$. The midpoint of the first, lower distribution function $\left(D_{a, 2}\right)$ can be regarded as the diameter at which half of the doubly charged particles are activated; the midpoint of the second, upper distribution function $\left(D_{a, 1}\right)$ is taken as the diameter at which half of the singly charged particles are activated $\left(D_{a}\right)$. However, this technique is only applicable when there are enough data points at the plateau of the doubly charged particles to be fitted. Moreover, it assumes that the fraction of doubly charged particles is constant over the whole size range.

A simpler method to correct the CCN efficiency spectra for doubly charged particles, is to determine the fraction of activated doubly charged particles from the level of the lower plateau in the spectrum, $\left(N_{\mathrm{CCN}} / N_{\mathrm{CN}}\right)_{2}$. Assuming that this fraction is constant over the whole particle size range, the activated fraction of singly charged particles, $\left(N_{\mathrm{CCN}} / N_{\mathrm{CN}}\right)_{1}$, can be calculated from the measured number concentrations as follows:

$\left(N_{\mathrm{CCN}} / N_{\mathrm{CN}}\right)_{1}=\frac{N_{\mathrm{CCN}}-N_{\mathrm{CN}} \cdot\left(N_{\mathrm{CCN}} / N_{\mathrm{CN}}\right)_{2}}{N_{\mathrm{CN}}-N_{\mathrm{CN}} \cdot\left(N_{\mathrm{CCN}} / N_{\mathrm{CN}}\right)_{2}}$ 
The function given in Eq. (1) is then fitted to the corrected $\mathrm{CCN}$ efficiency spectrum $\left(\left(N_{\mathrm{CCN}} / N_{\mathrm{CN}}\right)_{1}\right.$ vs. $\left.D\right)$ to obtain $D_{a}$.

The effects of doubly charged particles on the CCNC calibration results will be discussed in Sect. 3.1. In this study, corrections for doubly charged particles have been applied only in the data processing of experiments where the fraction of activated doubly charged particles, $\left(N_{\mathrm{CCN}} / N_{\mathrm{CN}}\right)_{2}$, exceeded the value of 0.1 , unless mentioned otherwise.

\subsubsection{Correction for DMA transfer function}

Ideally, the CCN efficiency spectra of internally mixed aerosols should have the shape of a step function, where all particles larger than the critical dry diameter $\left(D_{c}\right)$ are activated $\left(N_{\mathrm{CCN}} / N_{\mathrm{CN}}=1\right)$ and all smaller particles are nonactivated $\left(N_{\mathrm{CCN}} / N_{\mathrm{CN}}=0\right)$. The particle size resolution that can be achieved upon selection of a monodisperse aerosol with a DMA, however, is limited by the transfer function of the DMA. Thus the selected monodisperse aerosol consists not only of particles with the selected nominal mobility equivalent diameter, but it also contains smaller and larger particles. The activation of these particles results in a widening of the observed $\mathrm{CCN}$ efficiency spectrum, i.e., to a gradual rather than stepwise increase of $N_{\mathrm{CCN}} / N_{\mathrm{CN}}$ with $D$ (see Fig. 4). Due to the asymmetry of the DMA transfer function, the widening does not only increase the standard deviation of the cumulative Gaussian distribution fit function $(\sigma)$, but it can also shift the midpoint of the $\mathrm{CCN}$ efficiency spectrum $\left(D_{a}\right)$. The transfer function effect can be corrected by transforming each of the experimentally selected nominal mobility equivalent diameters $\left(D_{\text {nom }}\right)$ into an effective diameter $\left(D_{\text {eff }}\right) . \quad D_{\text {eff }}$ is the diameter for which the fraction of selected particles with diameters $\geq D_{\text {eff }}$

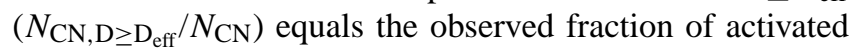
particles $\left(N_{\mathrm{CCN}} / N_{\mathrm{CN}}\right)$.

To correct for the transfer function effect, the following procedure can be applied to each data point in the $\mathrm{CCN}$ efficiency spectrum:

1. The nominal electrical mobility, $Z_{\text {nom }}$, which corresponds to the selected nominal electrical mobility diameter $D_{\text {nom }}$ is calculated according to standard DMA equations, inserting the operating conditions and dimensions of the DMA (Willeke and Baron, 2001).

2. The half-width of the transfer function is calculated from the relation $\Delta Z_{\mathrm{nom}}=Z_{\mathrm{nom}} Q_{\mathrm{ae}} / Q_{\mathrm{sh}}$, where $Q_{\mathrm{ae}}$ is the aerosol flow and $Q_{\mathrm{sh}}$ is the sheath air flow through the DMA (Knutson and Whitby, 1975).

3. The lower and upper boundaries of the transfer function on the scale of electrical mobility are calculated as $Z_{l}=Z_{\text {nom }}+\Delta Z_{\text {nom }}$ and $Z_{u}=Z_{\text {nom }}-\Delta Z_{\text {nom }}$, respectively. The corresponding lower and upper boundaries of the transfer function on the scale of particle diameter, $D_{l}, D_{u}$, are calculated according to standard DMA equations (Willeke and Baron, 2001). The theoretical transfer function of the DMA at the selected particle size, $P_{\text {nom }}$, is given as a piecewise linear probability function of triangular shape which is 0 for $D \leq D_{l}, 1$ at $D_{\text {nom }}$, and again 0 for $D \geq D_{u}$ (Willeke and Baron, 2001).

4. The number size distribution function of the monodisperse aerosol at the selected particle size, $\psi_{m}$, is calculated by multiplying $P_{\text {nom }}$ with the size distribution function of polydisperse calibration aerosol, $\psi_{p}$, which was measured in parallel to the $\mathrm{CCN}$ efficiency measurements. Note that $P_{\text {nom }}$ can be used instead of $\psi_{m}$ if the investigated polydisperse aerosol has a broad size distribution that does not vary strongly over the width of the transfer function (this is typically the case for ambient aerosols).

5. The corrected (effective) diameter $\left(D_{\text {eff }}\right)$ is calculated by numerical iteration to reproduce the $\mathrm{CCN}$ efficiency observed at the selected diameter with the following relation:

$$
N_{\mathrm{CCN}} / N_{\mathrm{CN}}=\frac{\int_{D_{\mathrm{eff}}}^{D_{u}} \psi_{m} d D}{\int_{D_{l}}^{D_{u}} \psi_{m} d D}
$$

The application of the transfer function correction requires that the maximum value of the $\mathrm{CCN}$ efficiency spectrum equals the true maximum $\mathrm{CCN}$ efficiency of the investigated aerosol particles passing through the DMA, i.e. unity for our salt calibration aerosols (normalization of the observed values of $N_{\mathrm{CCN}} / N_{\mathrm{CN}}$ with $0.5 / a$ if $a \neq 0.5$ ). Otherwise the correction would refer to an unrealistic $\mathrm{CCN}$ efficiency that is caused by different particle losses and counting efficiencies of the CPC and CCNC, and it would lead to a distorted CCN efficiency spectrum and $D_{a}$.

Moreover, the above correction is based on the assumption that the particles are internally mixed and exhibit no significant differences in composition over the size range of the transfer function and monodisperse aerosol, respectively. Under this assumption, it can also be applied to CCN efficiency spectra of atmospheric aerosols.

Note that both the width of the transfer function and the width of the $\mathrm{CCN}$ spectrum increase with increasing aerosol to sheath flow ratio in the DMA. $D_{\text {a }}$ can shift to larger or smaller sizes (i.e., $D_{\text {eff }}>D_{\text {nom }}$ or $D_{\text {eff }}<D_{\text {nom }}$, respectively), depending on the shape of the particle size distribution. The effects of the DMA transfer function on the CCNC calibration results will be discussed in Sect. 3.2. In this study, corrections for the DMA transfer function have been applied only where explicitly mentioned. 


\subsubsection{Correction for particle shape}

In a DMA, the particle size is selected according to the electrical mobility equivalent diameter, which assumes a spherical shape of the particles. In the case of non-spherical particles, the mobility equivalent diameter $\left(D_{B}\right)$ selected by the DMA is generally larger than the mass equivalent diameter $\left(D_{m}\right)$. Thus the application of mobility equivalent diameters for Köhler model calculations can lead to an underestimation of the effective supersaturation in the CCNC. Sodium chloride particles generated by nebulization of a $\mathrm{NaCl}$ solution and subsequent drying are usually of cubic shape (Scheibel and Porstendörfer, 1983; Krämer et al., 2000; Mikhailov et al., 2004). Also ammonium sulfate particles generated by nebulization and drying may not be fully spherical and compact (Biskos et al., 2006a).

The effects of particle shape and porosity can be described with the dynamic shape factor $\chi$, which is defined as the ratio of the drag force experienced by the particle in question to that of a sphere of equivalent mass (Krämer et al., 2000):

$\chi=\frac{D_{B} C\left(D_{m}\right)}{D_{m} C\left(D_{B}\right)}$

in which $C\left(D_{B}\right)$ and $C\left(D_{m}\right)$ are the slip correction factors for the respective diameters $D_{B}$ and $D_{m} . C(D)$ can be approximated by the empirical relation (Willeke and Baron, 2001):

$C(D)=1+\frac{2 \lambda}{D}\left(1.142+0.558 \exp \left(-0.999 \frac{D}{2 \lambda}\right)\right)$

in which $\lambda$ is the mean free path of the gas molecules ( $\lambda=68 \mathrm{~nm}$ in air at $298 \mathrm{~K}$ and standard atmospheric pressure).

When applying a shape correction, the particle diameters selected by the DMA $\left(D=D_{B}\right)$ have to be transformed into mass equivalent diameters $D_{m}$ by iteratively solving Eq. (4) with Eq. (5). Upon CCNC calibration, the transformation of $D=D_{B}$ into $D_{m}$ can be performed for the complete CCN efficiency spectrum prior to fitting, or just for the activation diameter obtained from a fit to the uncorrected spectrum. Both approaches lead to the same value of a shape-corrected activation diameter $D_{a}$, which can then be taken as the critical dry particle diameter for Köhler model calculations to determine the effective supersaturation in the CCNC as described below.

For ammonium sulfate particles generated by nebulization, a shape factor of $\chi=1.02$ has been recommended (Biskos et al., 2006a). For sodium chloride particles, different shape factors have been used: a constant value of $\chi=1.08$ (e.g., Krämer et al., 2000; Mikhailov et al., 2004) or sizedependent values in the range of 1.08-1.24 (Biskos et al., 2006b; DeCarlo et al., 2004).

The effects of different shape corrections on the calibration results will be discussed in Sect. 3.8. In this study, corrections for particle shape have been applied only where explicitly mentioned.

\subsubsection{Determination of effective supersaturation $\left(S_{\text {eff }}\right)$}

The diameter at which the $\mathrm{CCN}$ efficiency spectrum reaches half its maximum, i.e., the activation diameter $D_{a}$ as obtained from the fit to the experimental data (with or without corrections for doubly charged particles, DMA transfer function, and particle shape), can be regarded as the critical dry particle diameter for $\mathrm{CCN}$ activation, $D_{c}$, i.e., the diameter that is required for particles of the given composition to be activated as $\mathrm{CCN}$ at the given supersaturation.

For soluble materials, $D_{c}$ can be taken as the mass equivalent diameter of the dry solute particle, $D_{s}$, and through Köhler theory it can be related to the critical supersaturation $\left(S_{c}\right)$, which is the minimum supersaturation required to activate particles of the given size and composition as CCN. $S_{c}$ in turn can be regarded as the effective water vapor supersaturation in the CCNC ( $\left.S_{\text {eff }}\right)$ at the given operating conditions $\left(\Delta T, p, T_{1}, Q\right)$. Thus Köhler model calculations as detailed in Appendix A were performed to determine $S_{\text {eff }}\left(=S_{c}\right)$ from $D_{a}\left(=D_{s}\right)$, using the Köhler model VH4 and inserting $T_{1}$ for $T$ unless mentioned otherwise.

From each of the multiple $\mathrm{CCN}$ efficiency spectra recorded at each of the temperature differences investigated within a calibration experiment, we obtained one data point in a calibration diagram of $S_{\text {eff }}$ vs. $\Delta T$. A linear calibration function, $f_{s}=k_{s} \Delta T+S_{0}$, was obtained by a linear leastsquares fit to these data points. One exemplary calibration line is illustrated in Fig. 2b. The fit parameters of the calibration function $\left(k_{s}, S_{0}\right)$ can be used in the CCNC software to calculate and set appropriate temperature differences, $\Delta T$, for $\mathrm{CCN}$ measurements at desired water vapor supersaturations, $S_{\text {eff. }}$.

\subsection{CCNC flow model}

Roberts and Nenes (2005) introduced a model that describes the relationship between the temperature difference and $S_{\text {eff }}$ in the DMT-CCNC column under certain operating conditions. Input variables to the model are the volumetric flow rate, the sheath-to-aerosol flow ratio, the pressure, and the inner wall streamwise temperature difference $\left(\Delta T_{\text {inner }}\right)$ between the exit and the entrance of the column. Lance et al. (2006) compared the simulated instrument responses for calibration aerosol against actual measurements. They indicated that the supersaturation strongly depends on $\Delta T_{\text {inner }}$ which may be only a fraction of the temperature difference imposed by the TECs at the outer wall of the column $\left(\Delta T=T_{3}-T_{1}\right)$. It is assumed that the inner temperature at the entrance of the column $\left(T_{1 \text {,inner }}\right)$ equals the entrance temperature measured outside the column, i.e., $T_{1}$. The temperature drop across the wall - the quotient of $\Delta T_{\text {inner }}$ to $\Delta T-$ is called the thermal efficiency $\eta(\eta \leq 1)$ and varies with the operating conditions. $\eta$ has to be determined to predict the $S_{\text {eff }}$ of the instrument and can be calculated if the thermal resistance $\left(R_{T}\right)$ of the column is known. 
Following the procedure suggested by Lance et al. (2006), we calibrated the thermal resistance of our instrument before estimating the thermal efficiency and the supersaturation in the CCNC under different operating conditions. The supersaturation was first determined experimentally by calibrating the $\mathrm{CCN}$ counter with ammonium sulfate particles of known size at different $\Delta T$ values and inferring $S_{\text {eff }}$ by converting the critical diameter into $S_{c}$ via Köhler model calculations. The calibration line ( $S_{\text {eff }}$ vs. $\left.\Delta T\right)$ did not go through the origin of the coordinate system, but intercepted the $\mathrm{x}$-axis at a certain $\Delta T_{0}$ (cf. Fig. 2b). Since the model assumes that $S=0$ if $\Delta T_{\text {inner }}=0$ and thus $\Delta T=0$, we shifted the calibration line to the left by subtracting its $\Delta T_{0}$ from each $\Delta T$, which led to a new calibration line of $S_{\text {eff }}$ vs. $\Delta T^{*}\left(\Delta T^{*}=\Delta T-\right.$ $\left.\Delta T_{0}\right)$. Each pair of $\Delta T^{*}$ and $S_{\text {eff }}$ was taken to determine $\Delta T_{\text {inner }}$ by solving Eq. (16) in Lance et al. (2006) iteratively. The corresponding thermal efficiency $\eta$ was calculated dividing $\Delta T_{\text {inner }}$ by $\Delta T^{*}$, and the corresponding thermal resistance $R_{\mathrm{T}}$ was calculated by solving Eq. (15) in Lance et al. (2006).

An average value of $R_{\mathrm{T}}$ was taken as the effective thermal resistance of the CCNC and used to model the effective supersaturation for various operating conditions $\left(T_{1}, p, Q\right)$ as follows: For a given $\Delta T, \Delta T^{*}$ was calculated by subtracting a standard offset value of $\Delta T_{0}=1 \mathrm{~K}$ (or $\Delta T_{0}=2 \mathrm{~K}$ for $Q=1 \mathrm{~L} \mathrm{~min}^{-1}$ ) and inserted into Eq. (15) of Lance et al. (2006) to calculate $\eta$. The inner wall temperature difference, $\Delta T_{\text {inner }}$, was determined by multiplication of $\eta$ with $\Delta T^{*}$, and finally, $S_{\text {eff }}$ was calculated using Eq. (16) of Lance et al. (2006).

\section{Results and discussion}

3.1 Effect of doubly charged particles on CCN efficiency spectra

Figure 3 shows exemplary CCN efficiency spectra and fit curves used to determine the dry particle activation diameter, $D_{a}$, which is the basis for calculating the effective water vapor supersaturation in the CCNC, $S_{\text {eff }}$ (Sect. 2.3.2). As outlined in Sect. 2.3.1.2, CCN efficiency spectra recorded by particle size selection with a differential mobility analyzer can be influenced by doubly charged particles (Fig. 3) which interfere with the determination of $D_{a}$.

The measured spectrum in Fig. 3a exhibits a high fraction of activated doubly charged particles (plateau level $\sim 0.17$ ). The fit with a single cumulative Gaussian distribution function (Eq. 1) strongly deviated from the measured data points and gave a $D_{a}$ value $\sim 2 \%$ smaller than the value obtained by fitting with two distribution functions. After correcting the measured spectrum with Eq. (2), the fit of Eq. (1) to the corrected spectrum gave the same $D_{a}$ value as the fit of two distribution functions to the uncorrected spectrum, which can be regarded as the actual activation diameter. The $\sim 2 \%$ de-
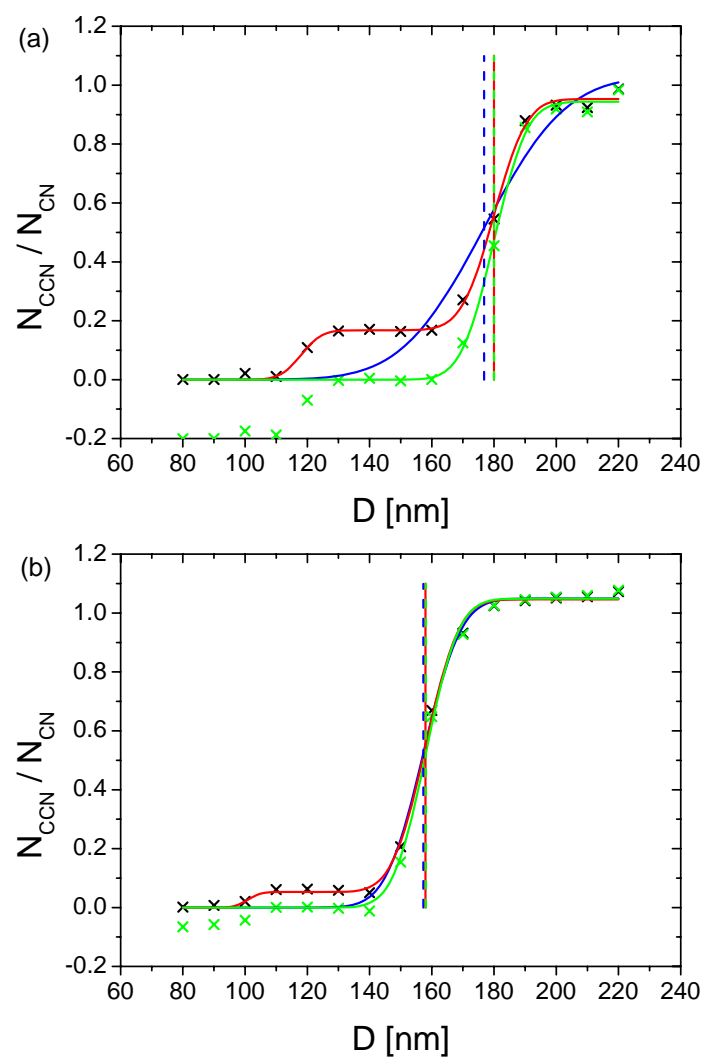

Fig. 3. Alternative fitting methods and dry particle activation diameters $\left(D_{a}\right)$ for exemplary CCN efficiency spectra of ammonium sulfate with (a) high and (b) low fractions of doubly charged particles. The black crosses are measured data points. The green crosses are data points obtained by correction with Eq. (2). The solid blue line is the fit of a cumulative Gaussian distribution function (Eq. 1) to the measured spectrum, and the solid green line is the fit of Eq. (1) to the corrected spectrum. The solid red line is the fit of two distribution functions to the measured spectrum. The vertical dashed lines are the $D_{a}$ values obtained from the fit curves with the same color.

crease of $D_{a}$ led to a $\sim 3 \%$ relative increase of the effective supersaturation determined by Köhler model calculations.

The measured spectrum in Fig. $3 \mathrm{~b}$ exhibits a low fraction of activated doubly charged particles (plateau level $\sim 0.06$ ), and the fit with a single cumulative Gaussian distribution function (Eq. 1) agrees well with all data points at $N_{\mathrm{CCN}} / N_{\mathrm{CN}}$ $>0.1$. Therefore, the $D_{a}$ value obtained from this fit was only $\sim 0.5 \%$ smaller than the values obtained after correcting the spectrum with Eq. (2), or fitting with two distribution functions. The corresponding relative change of $S_{\text {eff }}$ was only $0.7 \%$.

In our study, the observed fraction of activated doubly charged particles was generally in the range of $0-0.25$. In most cases the fraction was $<0.1$ and a single cumulative Gaussian distribution (Eq. 1) fitted to the data points 

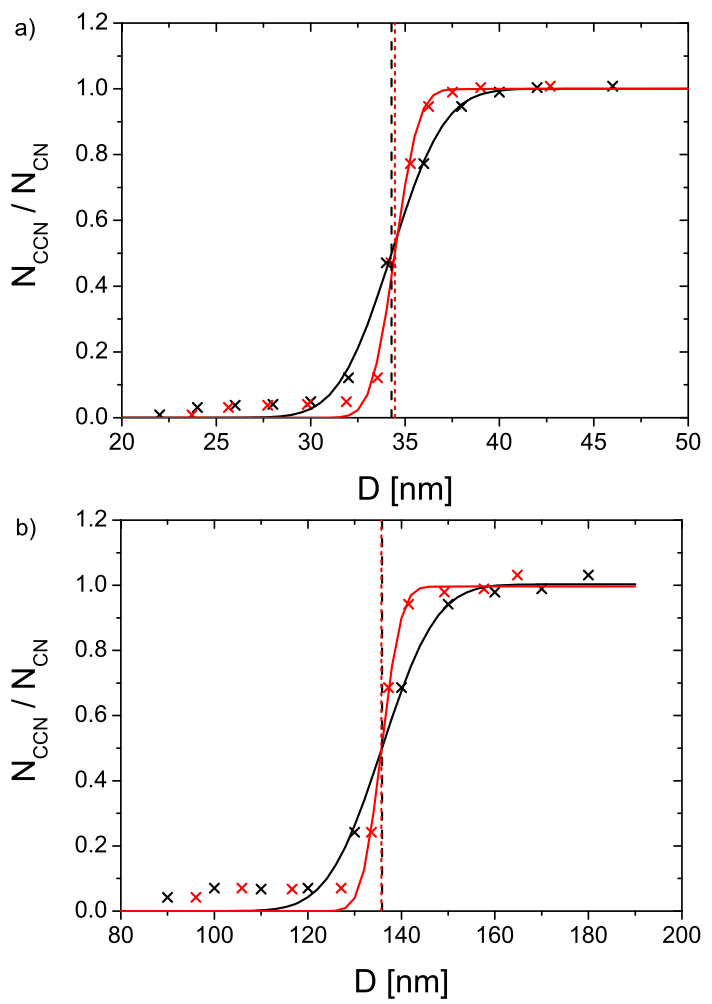

Fig. 4. Correction for DMA transfer function in exemplary $\mathrm{CCN}$ efficiency spectra of ammonium sulfate with (a) small and (b) large dry particle activation diameter $\left(D_{a}\right)$. The black crosses are measured data points. The red crosses are data points obtained by correction according to Sect. 2.3.1.3. The solid lines are fits of a cumulative Gaussian distribution function (Eq. 1) to the measured and corrected spectra, respectively. The vertical dashed lines are the $D_{a}$ values obtained from the fit curves with the same color.

was used to determine $D_{a}$ (relative deviations of $D_{a}$ and $S_{\text {eff }} \leq 1 \%$ ). For plateau levels $>0.1$, two cumulative Gaussian distributions were used.

\subsection{Effect of DMA transfer function on CCN efficiency spectra}

Figure 4 shows exemplary CCN efficiency spectra with and without correction for the DMA transfer function as described in Sect. 2.3.1.3. The correction leads to narrower $\mathrm{CCN}$ efficiency spectra with steeper slopes and smaller standard deviations of the fit function (uncorrected $\sigma / D_{a} \approx 7 \%$, corrected $\left.\sigma / D_{a} \approx 3 \%\right)$. The small residual values of $\sigma \mathrm{ob}-$ tained after correction $(<1-4 \mathrm{~nm})$ indicate high precision of the experiments; they can be attributed to small heterogeneities of the supersaturation profile in the CCNC or other non-idealities such as particle shape effects. Depending on the size distribution of the polydisperse calibration aerosol and of the monodisperse aerosol selected by the DMA (Sect. 2.3.1), the correction can shift $D_{a}$ either towards smaller or towards larger diameters. In the above example and other tests, however, the influence on $D_{a}$ and $S_{\text {eff }}$ was very small (relative changes $<1 \%$ ), and thus the calibration results were generally not corrected for the DMA transfer function unless mentioned otherwise.

\subsection{Measurement precision within a laboratory experiment}

Figure 2a shows the CCN efficiency spectra of an exemplary calibration experiment with ammonium sulfate particles. The experiment lasted for $26 \mathrm{~h}$ and was performed in the laboratory under stable conditions: sample temperature $(296.3 \pm 0.2) \mathrm{K}$, CCNC column top temperature $T_{1}=(298.5 \pm 0.2) \mathrm{K}$, pressure $p=(1026 \pm 2) \mathrm{hPa}$ (mean value \pm standard deviation). The measurement data have been processed without applying any corrections for doubly charged particles, DMA transfer function, or particle shape.

Table 1 summarizes characteristic measurement parameters and results of the exemplary calibration experiment. For each of the 5 different $\Delta T$ values in the range of $2-16 \mathrm{~K}, 15$ $\mathrm{CCN}$ efficiency spectra have been recorded, and dry particle activation diameters $D_{a}$ in the range of 26-178 nm have been obtained by fitting with a cumulative Gaussian distribution function (Eq. 1). The 95\% confidence interval for $D_{a}$ was, on average, less than $2 \mathrm{~nm}$, which confirms the skill of the fit function used. The relative standard deviations of $D_{a}$ were only $0.3-1.4 \%$, indicating high instrument stability and measurement precision under constant surrounding conditions.

Using the $D_{a}$ values obtained from the individual CCN efficiency spectra, critical supersaturations $S_{c}$ were calculated as described in Sect. 2.3.2 and Appendix A4 (Köhler model VH4), and these were taken as the effective supersaturations of water vapor in the CCNC, $S_{\text {eff. }}$ As detailed in Table 1, the mean values of $S_{\text {eff }}$ for the selected temperature differences were in the range of $0.06-1.22 \%$, and the relative standard deviations were $0.5-2.2 \%$, increasing with decreasing supersaturation.

As illustrated in Fig. 2a, the upper limit values of the CCN efficiency spectra of the calibration aerosols (maximum activated fraction of particles) deviated generally less than $\sim 10 \%$ from the ideally expected value of 1 , indicating that the uncertainty of $\mathrm{CCN}$ efficiencies measured with the calibrated CCNC was on the order of $\pm 10 \%$. The accuracy of CCN concentration and efficiency measurements depends critically on particle losses in the experimental setup and on the counting efficiencies of the OPC used for the detection of activated particles/droplets (CCN) and of the CPC used for the measurement of total number concentration of size-selected aerosol particles $(\mathrm{CN})$. For the determination

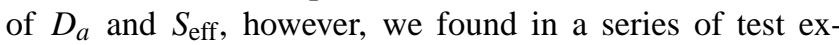
periments performed upon instrument maintenance that even strong variations of counting efficiency with particle size and concentration (deviations by up to $20 \%$ ) had no strong effect on the determination of $D_{a}$ and $S_{\text {eff }}$ (relative variations $<0.5 \%)$. 
Table 1. Measured and calculated parameters (arithmetic means and standard deviations) for the experiment shown in Fig. 2.

\begin{tabular}{ccccccccc}
\hline mean $\Delta T$ & stdev. $\Delta T$ & mean $D_{a}$ & rel. stdev. $D_{a}$ & $\begin{array}{c}\text { mean conf. } \\
\text { interv. of } D_{a} \\
{[\mathrm{~nm}]}\end{array}$ & $\begin{array}{c}\text { mean } S_{\text {eff }} \\
{[\%]}\end{array}$ & $\begin{array}{c}\text { rel. stdev. } S_{\text {eff }} \\
{[\%]}\end{array}$ & $\begin{array}{c}S_{\text {eff }} \text { from } \\
\text { calbr. line fit } \\
{[\%]}\end{array}$ & $\begin{array}{c}\text { rel. dev. of } \\
S_{\text {eff }} \text { from fit } \\
{[\%]}\end{array}$ \\
\hline 1.84 & {$[\mathrm{~K}]$} & {$[\mathrm{nm}]$} & {$[\%]$} & 1.7 & 0.062 & 2.2 & 0.044 & 38.5 \\
5.10 & 0.02 & 178.3 & 1.4 & 0.9 & 0.6 & 0.318 & 1.3 & 0.317 \\
7.71 & 0.03 & 44.7 & 0.6 & 0.3 & 0.519 & 0.9 & 0.536 & 3.2 \\
11.66 & 0.02 & 32.8 & 0.6 & 0.2 & 0.840 & 1.0 & 0.867 & 3.1 \\
15.59 & 0.02 & 25.8 & 0.3 & 0.6 & 1.223 & 0.5 & 1.197 & 2.2 \\
\hline
\end{tabular}

Figure $2 \mathrm{~b}$ shows the calibration line of $S_{\text {eff }}$ vs. $\Delta T$, which is a linear fit to the data points obtained from each of the recorded $\mathrm{CCN}$ efficiency spectra (Sect. 2.3.2). The corresponding calibration function is $S_{\text {eff }}=0.0838 \Delta T-0.1097$ with $R^{2}=0.9974(n=75)$. As detailed in Table 1 , the fit line agrees well with the experimentally determined data points at $S_{\text {eff }}>0.1 \%$ : the relative deviations hardly exceed $3 \%$. In spite of the high $R^{2}$ value, however, the relative deviation between fit line and data points at the lowest supersaturation ( $S_{\text {eff }} \approx 0.06 \%$ ) is as high as $38 \%$. Apparently the dependence of $S_{\text {eff }}$ on $\Delta T$ is not linear in this range, which is also indicated by the non-zero intercept of the calibration line with the $\mathrm{x}$-axis (as discussed below) and needs to be taken into account for CCN measurements at low supersaturation. For studies aiming at high accuracy of $S_{\text {eff }}$, a second or third order polynomial may in fact be more appropriate than the linear calibration function.

3.4 Variability within and between different measurement campaigns

Over the past years, we have operated and calibrated our DMT-CCNC at a variety of locations and elevations: during two one-month field campaigns in Guangzhou and Beijing, China (close to sea level); at our home laboratory in Mainz and another laboratory in Leipzig, Germany (close to sea level); and at the mountain stations Hohenpeissenberg, Germany (900 m a.s.1.), and Jungfraujoch, Switzerland (3570 $\mathrm{m}$ a.s.1.). An overview of the calibration results is given in Fig. 5.

During the field campaign in Guangzhou (Fig. 5a), the CCNC was operated with a flow rate of $0.5 \mathrm{~L} \mathrm{~min}^{-1}$ at a pressure of $\sim 1020 \mathrm{hPa}$, and the column top temperature $T_{1}$ varied between 298 and $303 \mathrm{~K}$. An average calibration line of $S_{\text {eff vs. }} \Delta T$ for the whole campaign was obtained by a fit to all data points, excluding the experiment with $T_{1}=303.2 \mathrm{~K}$, which was not representative for the rest of the campaign. Apart from this exceptional experiment, the deviations between individual calibration lines and the average line were at most $5-7 \%$ (relative) with regard to $S_{\text {eff }}$. As will be discussed in more detail below (Sect. 3.6), $S_{\text {eff }}$ and the slope of the calibration lines decreased with increasing $T_{1}$.
The calibration lines from the field campaign in Beijing ( $Q=0.5 \mathrm{~L} \mathrm{~min}^{-1}, p \approx 1020 \mathrm{hPa}$; Fig. 5b) exhibited a similar pattern and influence of $T_{1}$, and the maximum deviations between individual lines and the average line were again in the range of $5-7 \%$ (relative).

Before and after the field campaigns, we calibrated the CCNC in our home laboratory (Mainz, $p \approx 1020 \mathrm{hPa}$ ). In December 2005, we performed a series of five calibration experiments extending over several days without changing the experimental setup. The instrument was stopped in between measurement runs only to test the influence of small variations in the experimental conditions (changes of liquid water flow in the CCNC, dilution flow in aerosol generation, etc.). The resulting calibration lines are shown in Fig. 5c; the deviations between individual lines and the average were at most $2 \%$ (relative).

In 2006, we performed three more laboratory calibration experiments, where the time between each experiment was over one month and the experimental setup was newly arranged every time. The resulting three calibration lines also deviated not more than $2-3 \%$ from the corresponding average. As illustrated in Fig. 5c, the slope of the average calibration line from the series of experiments in 2006 was considerably smaller ( $10 \%$ relative) than the slope of the average line obtained from the experiments in 2005. Only about half the difference can be attributed to higher temperatures during the 2006 experiments. The remaining difference is most likely due to usage- and aging-related changes of instrument properties (e.g., porosity and thermal resistance of the CCNC column; A. Nenes, personal communication, 2007).

Figure $5 \mathrm{~d}$ shows the calibration lines measured during field campaigns at mountain stations (Hohenpeissenberg, $900 \mathrm{~m}$ a.s.1.; Mt. Jungfraujoch, $3570 \mathrm{~m}$ a.s.1.) and in a laboratory near sea level (Leipzig, $100 \mathrm{~m}$ a.s.l.). It illustrates that the supersaturation obtained at a given $\Delta T$ decreases significantly with pressure, which will be discussed in more detail in Sect. 3.6. For the two field campaigns on Mt. Jungfraujoch we found a similar long-term trend as for the lab experiments: the slopes of the calibration lines recorded in 2007 were about $10 \%$ smaller than those recorded one year before. 

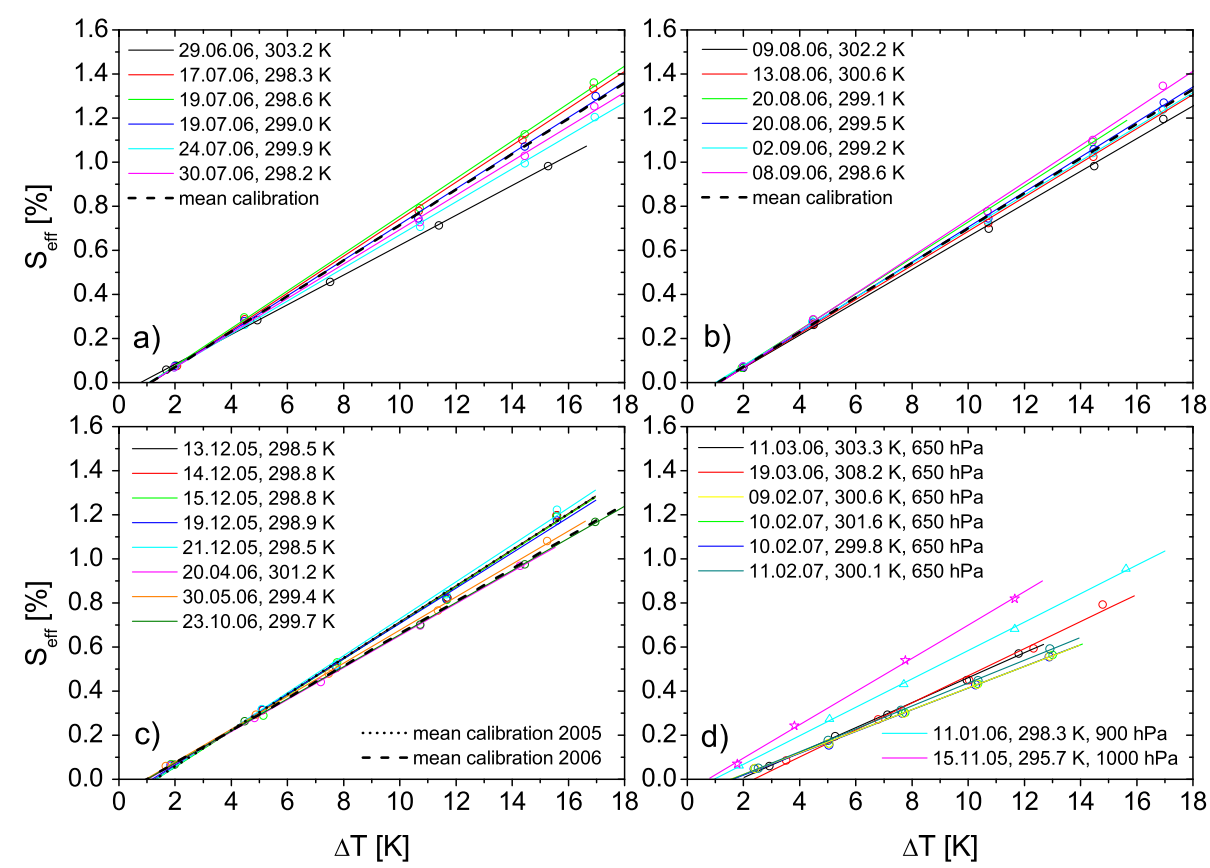

Fig. 5. Measured (symbols) and fitted (solid lines) calibration lines obtained from field and laboratory experiments with ammonium sulfate aerosol at different CCNC column top temperatures $\left(T_{1}\right)$ and different locations: (a) field campaign in Guangzhou, China; (b) field campaign in Beijing, China; (c) laboratory measurements in Mainz, Germany; (d) field campaigns at the mountain stations Hohenpeissenberg, Germany $(900 \mathrm{hPa})$ and Jungfraujoch, Switzerland $(650 \mathrm{hPa})$ and laboratory measurement in Leipzig, Germany $(1000 \mathrm{hPa})$. The CCNC was operated at $Q=0.5 \mathrm{~L} \mathrm{~min}^{-1}$ and $p \approx 1020 \mathrm{hPa}$ unless mentioned otherwise. The dotted and dashed black lines are mean calibration lines (see text).

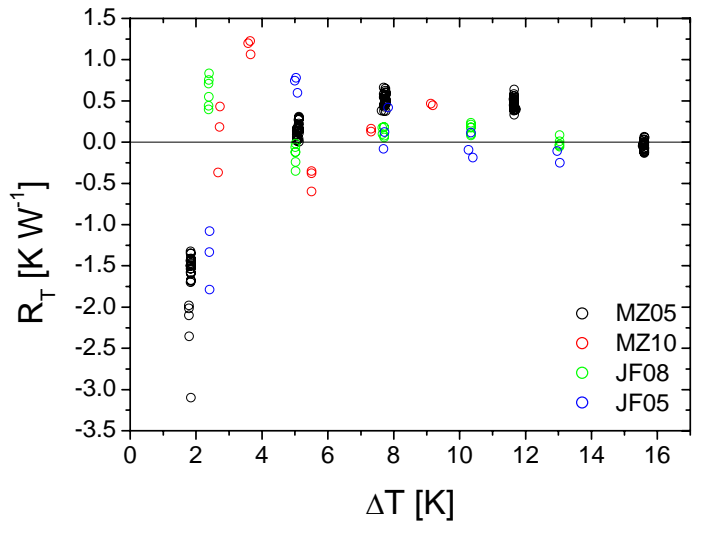

Fig. 6. Thermal resistance derived from four CCNC calibration experiments with ammonium sulfate aerosol at different pressures and flow rates (MZ05, MZ10, JF08, JF05, cf. Table 2) by fitting the CCNC flow model of Lance et al. (2006).

\subsection{Application of the CCNC flow model}

Lance et al. (2006) have presented a flow model describing the dependence of $S_{\text {eff }}$ on temperature, pressure, and flow rate in the CCN counter. According to this model, the water vapor supersaturation in the CCNC increases linearly with the temperature gradient and equals zero at $\Delta T=0$. As shown in Fig. 5, however, the experimentally determined calibration lines of $S_{\text {eff }}$ vs. $\Delta T$ generally do not intercept the $\mathrm{x}$-axis at $\Delta T=0$. Instead, the calibration lines obtained at $Q=0.5 \mathrm{~L} \mathrm{~min}^{-1}$ and $900-1020 \mathrm{hPa}$ intercepted the $\mathrm{x}$-axis at an offset around $1 \mathrm{~K}$, and those obtained at $650 \mathrm{hPa}$ at $1.5-$ $2.3 \mathrm{~K}$. The $\Delta T$ offset values of calibration lines determined under other conditions (not included in Fig. 5) were: 1.31.5 at $Q=0.8 \mathrm{~L} \mathrm{~min}^{-1}$ and $650 \mathrm{hPa} ; 1.9-2.2 \mathrm{~K}$ at $1.0 \mathrm{~L} \mathrm{~min}^{-1}$ and $\sim 1000 \mathrm{hPa}$. To make the model applicable to our experimental results, we have subtracted the offset values $\left(\Delta T_{0}\right)$ as detailed in Sect. 2.4 .

Four calibration experiments performed at different locations, altitudes and flow rates (cf. Table 2; MZ05, MZ10, JF05, JF08) were used to determine the thermal resistance $\left(R_{T}\right)$ of our $\mathrm{CCN}$ instrument as suggested by Lance et al. (2006) but using the Köhler model VH4 rather than the Köhler model VH4.b, which had been used by Lance et al. Figure 6 shows the calculated values of $R_{T}$ plotted against $\Delta T$. The $R_{T}$ values exhibit substantial deviations between different calibration experiments and operating conditions. Especially at low $\Delta T$, we obtained also strongly negative values of $R_{T}$, which are physically not realistic because they would correspond to thermal efficiencies $>100 \%$ (indicating that the temperature gradient inside the column would be larger than outside). Most likely, these $R_{T}$ values were affected by non-idealities, which also caused the non-linear 
Table 2. Calibration experiments used to test the CCNC flow model: experimental conditions and parameters of the linear calibration function.

\begin{tabular}{lllccccc}
\hline name & date & location & $\begin{array}{c}\mathrm{p} \\
{[\mathrm{hPa}]}\end{array}$ & $\begin{array}{c}\mathrm{Q} \\
{\left[\mathrm{L} \mathrm{min}{ }^{-1}\right]}\end{array}$ & $\begin{array}{c}\mathrm{T}_{1} \\
{[\mathrm{~K}]}\end{array}$ & $\begin{array}{c}\text { slope } k_{S} \\
{\left[\% \mathrm{~K}^{-1}\right]}\end{array}$ & $\begin{array}{c}\text { intercept } S_{0} \\
{[\%]}\end{array}$ \\
\hline MZ05 & 19 Dec 2005 & Mainz, lab & 1023 & 0.5 & 298.9 & 0.0802 & -0.0945 \\
MZ10 & 23 Dec 2005 & Mainz, lab & 1021 & 1.0 & 298.4 & 0.1608 & -0.3515 \\
JF08 & 8 Feb 2007 & Jungfraujoch, field & 650 & 0.8 & 299.3 & 0.0804 & -0.111 \\
JF05 & 10 Feb 2007 & Jungfraujoch, field & 650 & 0.5 & 301.6 & 0.0490 & -0.0760 \\
HP05 & 11 Jan 2006 & Hohenpeissenberg, field & 902 & 0.5 & 298.3 & 0.0645 & -0.0604 \\
\hline
\end{tabular}

dependence of $S_{\text {eff }}$ on $\Delta T$ observed at low $\Delta T$. Thus only the $R_{T}$ values determined at $\Delta T \geq 3 \mathrm{~K}$ were used to calculate an arithmetic mean of $0.24 \mathrm{~K} \mathrm{~W}^{-1}$, which can be taken as the effective thermal resistance of our CCNC unit. Note, however, that the effective thermal resistance determined as suggested by Lance et al. (2006) and outlined above depends on the applied Köhler model. Using the VH4.b Köhler model as applied by Lance et al. (2006), we obtained an average $R_{T}$ value of $1.78 \mathrm{~K} \mathrm{~W}^{-1}$ for our CCNC column, which is still lower than but closer to the value reported by Lance et al. (2006) for their instrument $\left(3.4 \pm 0.5 \mathrm{~K} \mathrm{~W}^{-1}\right)$. As discussed below (Sect. 3.7), different Köhler models can yield substantially different results, and the $S_{\text {eff }}$ values predicted with CCNC flow models using effective thermal resistances that have been determined with different Köhler models can vary accordingly.

Using the flow model with $R_{T}=0.24 \mathrm{~K} \mathrm{~W}^{-1}$ and with a standard temperature offset of $\Delta T_{0}=1 \mathrm{~K}$ as described in Sect. 2.4, we have calculated model calibration lines for the exemplary flow conditions listed in Table 2 and compared them to the experimental calibration data obtained with the Köhler model VH4. As illustrated in Fig. 7, the model lines agree fairly well with the experimentally determined data also for the experiment HP05, which had not been included in the determination of $R_{T}$. The relatively high uncertainty of $R_{T}$ (Fig. 6: variability $\gg 100 \%$ ) appears to have only a relatively weak influence on the performance of the flow model.

At high supersaturation, the relative deviations between the flow model and measurement data of $S_{\text {eff }}$ were on average $+2 \%$ for MZ05, $+3 \%$ for JF08, $+6 \%$ for $\mathrm{JF} 05$, and $+8 \%$ for HP05. At low supersaturation $(<0.1 \%)$, however, the deviations increased up to $42 \%$ (relative). Obviously, the non-idealities and non-linear dependence of $S_{\text {eff }}$ on $\Delta T$ experimentally observed at low $\Delta T$ cannot be captured with the flow model that predicts a linear dependence.

For the MZ10 experiment performed at $Q=1.0 \mathrm{~L} \mathrm{~min}^{-1}$, the modeled $S_{\text {eff }}$ values were on average by a factor of $\sim 2$ too high when using $\Delta T_{0}=1 \mathrm{~K}$, but the relative deviations decreased to $\sim 20 \%$ when a more realistic offset of $\Delta T_{0}=2 \mathrm{~K}$ was used instead. The strong influence of $\Delta T_{0}$ severely limits the applicability of the flow model for the extrapolation of experimental calibration results to different operating con-

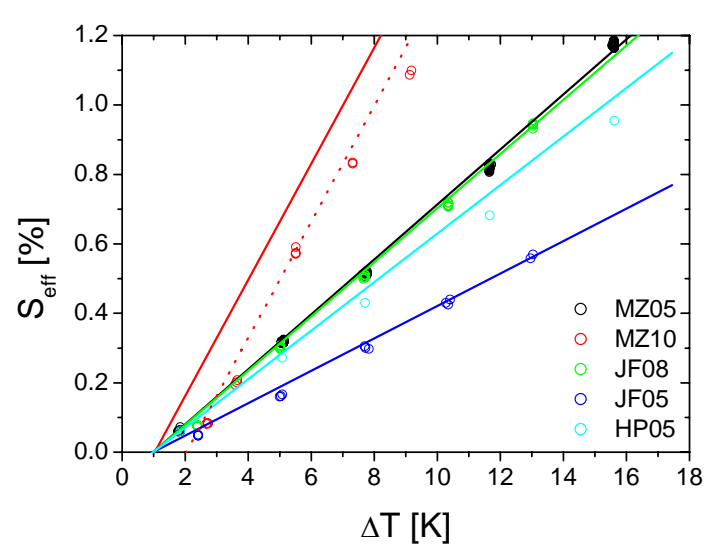

Fig. 7. Measured and modeled CCNC calibration lines obtained with ammonium sulfate aerosol under different operating conditions as detailed in Table 2. The circles are the effective supersaturation values calculated from measured dry particle activation diameters, and the lines are the corresponding flow model results (solid lines with $\Delta T_{0}=1 \mathrm{~K}$, dotted line with $\Delta T_{0}=2 \mathrm{~K}$ ).

ditions. As outlined above, $\Delta T_{0}$ has to be determined empirically and can vary substantially between different CCNC operating conditions, especially at high flow rates and low pressures (see Fig. 5d).

3.6 Dependence of supersaturation on temperature, pressure, and flow rate

As shown above, the relation between $S_{\text {eff }}$ and $\Delta T$ depends on $T_{1}, p$, and $Q$. Here we characterize and compare these dependences as observed in calibration experiments at different temperatures, pressures, and flow rates with the results of CCNC flow model calculations (cf. Sects. 2.4 and 3.5). To investigate the dependence of $S_{\text {eff }}$ on $T_{1}$, we used all calibration lines measured at a flow rate of $0.5 \mathrm{~L} \mathrm{~min}^{-1}$ and $\sim 1000 \mathrm{hPa}$ to calculate $S_{\text {eff }}$ at $\Delta T=5 \mathrm{~K}$, which corresponds to an inner-column temperature gradient of $\sim 8 \mathrm{~K} \mathrm{~m}^{-1}$ (subtraction of $\Delta T_{0} \approx 1 \mathrm{~K}$ and division of $\Delta T^{*} \approx 4 \mathrm{~K}$ by the column length of $0.5 \mathrm{~m}$; cf. Sect. 2.4). When plotted against $T_{1}$ (Fig. 8a), the experimentally determined $S_{\text {eff }}$ values exhibit a near linear decreasing trend with an average slope 

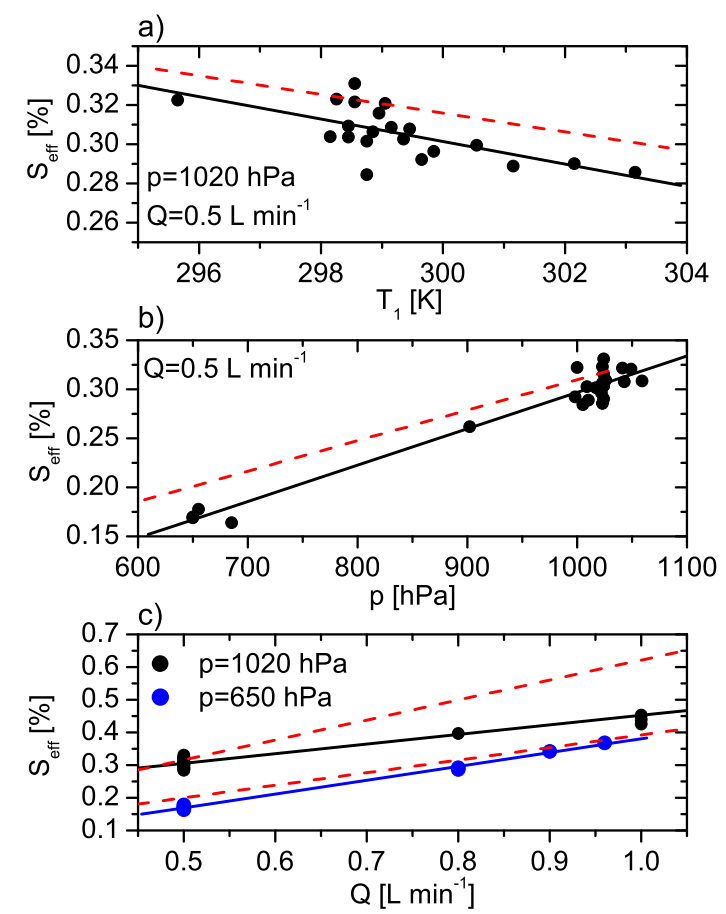

Fig. 8. Dependence of the effective supersaturation in the CCNC on (a) $T_{1}$, (b) pressure $(p)$, (c) flow rate $(Q)$. The data points are $S_{\text {eff }}$ values calculated from all recorded ammonium sulfate calibration lines (cf. Fig. 5) at $\Delta T=5 \mathrm{~K}$. The solid lines are linear fits to the data points and the dashed lines are the $S_{\text {eff values predicted by the }}$ CCNC flow model with $R_{\mathrm{T}}=0.24 \mathrm{~K} \mathrm{~W}^{-1}$.

of $\Delta S_{\text {eff }} / \Delta T_{1}=-0.0057 \% \mathrm{~K}^{-1}$. The observed dependence agrees fairly well with flow model calculations for the same conditions $\left(Q=0.5 \mathrm{~L} \mathrm{~min}^{-1}, \quad p=1020 \mathrm{hPa}\right.$, and $\left.\Delta T=5 \mathrm{~K}\right)$ yielding a slope of $\Delta S_{\text {eff }} / \Delta T_{1}=-0.0048 \% \mathrm{~K}^{-1}$. Both values are of similar magnitude but somewhat higher than the $-0.0034 \% \mathrm{~K}^{-1}$ calculated by Roberts and Nenes (2005) for an inner-column temperature gradient of $8.3 \mathrm{~K} \mathrm{~m}^{-1}$. Note, however, that the observed variability of $S_{\text {eff }}$ at $T_{1} \approx 299 \mathrm{~K}$ was of similar magnitude as the observed and modeled differences between $296 \mathrm{~K}$ and $303 \mathrm{~K}$.

Figure $8 \mathrm{~b}$ illustrates the dependence of $S_{\text {eff }}$ on pressure. All calibration lines presented in Fig. 5 were used to calculate the effective supersaturation at $\Delta T=5 \mathrm{~K}$, and the obtained values were plotted against pressure. The observed near-linear increase of $S_{\text {eff }}$ with $p$ was $0.037 \%$ per $100 \mathrm{hPa}$ at $Q=0.5 \mathrm{~L} \mathrm{~min}^{-1}$, which is of similar magnitude as the flow model result $(0.031 \%$ per $100 \mathrm{hPa})$ and the value reported by Roberts and Nenes (2005) $\left(\Delta S_{\text {eff }} / \Delta p=+0.03 \%\right.$ per $100 \mathrm{hPa}$ for $0.5 \mathrm{~L} \mathrm{~min}^{-1}$ and $8.3 \mathrm{~K} \mathrm{~m}^{-1}$ ).

Figure $8 \mathrm{c}$ shows the dependence of $S_{\text {eff }}$ on the flow rate of the CCNC. All calibration lines measured at $\sim 1020 \mathrm{hPa}$ and $\sim 650 \mathrm{hPa}$ were used to calculate $S_{\text {eff }}$ at $\Delta T=5 \mathrm{~K}$, and the obtained values were plotted against $Q$. The observed increase of $S_{\text {eff }}$ with $Q$ was $0.029 \%$ per $0.1 \mathrm{~L} \mathrm{~min}^{-1}$ at sea level, and
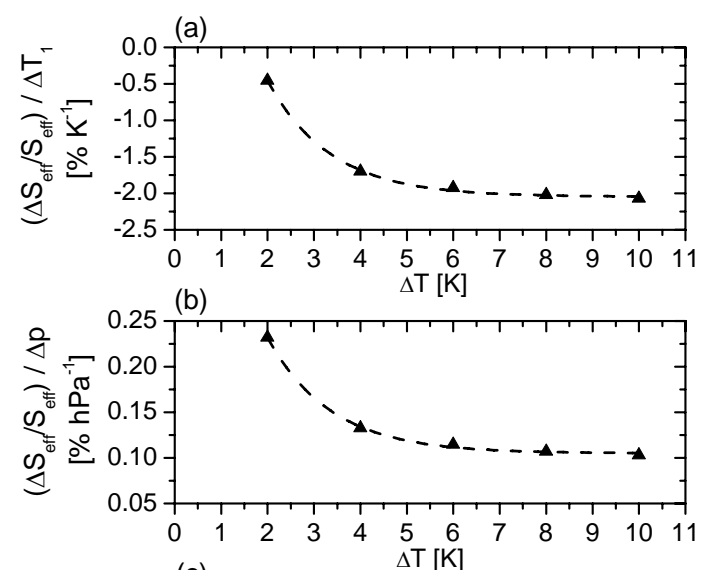

(c)

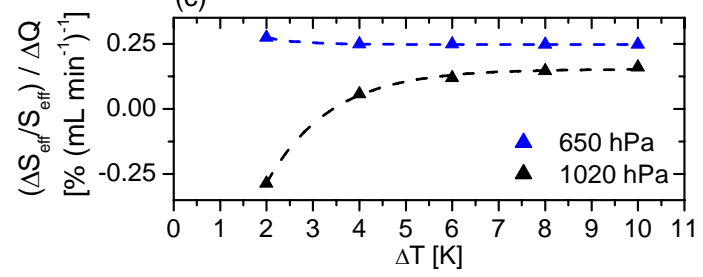

Fig. 9. Dependence of effective supersaturation on temperature $\left(T_{1}\right)$, pressure $(p)$, and flow rate $(Q)$ in the CCNC averaged over all calibration experiments with ammonium sulfate aerosol. Every data point corresponds to the slope of a linear fit to all values of $\Delta S_{\text {eff }} / S_{\text {eff }}$ at a given $\Delta T$ plotted against $T_{1}, p$, or $Q$, respectively. $\Delta S_{\text {eff }} / S_{\text {eff }}$ is the relative deviation between $S_{\text {eff from an individ- }}$ ual calibration line and the mean value of $S_{\text {eff }}$ for all calibrations performed at $Q=0.5 \mathrm{~L} \mathrm{~min}^{-1}$ and $p \approx 1020 \mathrm{hPa}$ (black triangles) or $650 \mathrm{hPa}$ (blue triangles), respectively. The dashed lines are firstorder exponential decay fit functions.

$0.042 \%$ per $0.1 \mathrm{~L} \mathrm{~min}^{-1}$ at high altitude. The model slopes were $\Delta S_{\text {eff }} / \Delta Q=+0.061 \%$ per $0.1 \mathrm{~L} \mathrm{~min}^{-1}$ at $1020 \mathrm{hPa}$ and $\Delta S_{\text {eff }} / \Delta Q=+0.038 \%$ per $0.1 \mathrm{~L} \mathrm{~min}^{-1}$ at $650 \mathrm{hPa}$, respectively. The corresponding value reported by Roberts and Nenes (2005) was $\Delta S_{\text {eff }} / \Delta Q=0.06 \%$ per $0.1 \mathrm{~L} \mathrm{~min}^{-1}$ for $1000 \mathrm{hPa}$ and $8.3 \mathrm{~K} \mathrm{~m}^{-1}$, which is the same as we obtained with the $\mathrm{CCN}$ flow model, but significantly higher than what we determined experimentally.

Figure 9 illustrates the observed average relative change of supersaturation $\left(\Delta S_{\text {eff }} / S_{\text {eff }}\right)$ caused by changes of column top temperature, pressure, and flow rate as a function of $\Delta T$.

The relative decrease of $S_{\text {eff }}$ with increasing $T_{1}$ was $\sim 2 \%$ $\mathrm{K}^{-1}$ at high $\Delta T$ and decayed near-exponentially to $\sim 0.5 \%$ $\mathrm{K}^{-1}$ at $\Delta T=2 \mathrm{~K}$ (Fig. 9a). The relative increase of $S_{\text {eff }}$ with increasing $p$ was $\sim 1 \%$ per $10 \mathrm{hPa}$ at high $\Delta T$ and grew nearexponentially to $\sim 2.3 \%$ per $10 \mathrm{hPa}$ at $\Delta T=2 \mathrm{~K}$ (Fig. $9 \mathrm{~b}$ ). At high $\Delta T$ the relative increase of $S_{\text {eff }}$ with increasing $Q$ was $\sim 15 \%$ per $0.1 \mathrm{~L} \mathrm{~min}^{-1}$ for the measurements at $p \approx 1020 \mathrm{hPa}$ and $\sim 25 \%$ per $0.1 \mathrm{Lmin}^{-1}$ at $p \approx 650 \mathrm{hPa}$ (Fig. 9c). For the $650 \mathrm{hPa}$ measurements, the deviation increased with decreasing $\Delta T$ to up to $\sim 30 \%$ per $0.1 \mathrm{~L} \mathrm{~min}^{-1}$ at $\Delta T=2 \mathrm{~K}$, but for the measurements at $\sim 1020 \mathrm{hPa}$ it decreased to almost 


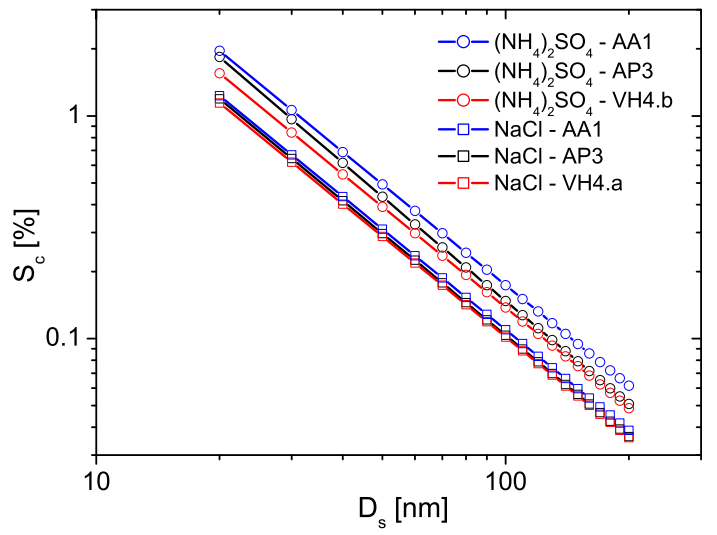

Fig. 10. Critical supersaturations $\left(S_{c}\right)$ calculated for ammonium sulfate and sodium chloride particles with dry particle mass equivalent diameters $\left(D_{S}\right)$ in the range of 20-200 nm using selected Köhler models from Table 3 with high (blue), intermediate (black), and low (red) $S_{C}(298.15 \mathrm{~K})$.

$-30 \%$ per $0.1 \mathrm{~L} \mathrm{~min}^{-1}$ at $\Delta T=2 \mathrm{~K}$. This divergence confirms that $\mathrm{CCN}$ measurements at low $\Delta T$ and $S_{\text {eff }}$, respectively, require careful experimental calibration, and that the possibilities for extrapolation to different operating conditions are limited.

\subsection{Deviations between different Köhler models}

To characterize the influence of different Köhler modeling approaches on the CCNC calibration and measurement data analysis, we have calculated critical supersaturations $\left(S_{c}\right)$ for ammonium sulfate and sodium chloride particles in the size range of 20-200 nm with a range of Köhler models and parameterizations/approximations of aqueous solution properties that are frequently used in $\mathrm{CCN}$ studies.

According to different mathematical formalisms, which are mostly determined by the underlying representation of water activity, we distinguish between activity parameterization (AP), osmotic coefficient (OS), van't Hoff factor $(\mathrm{VH})$, effective hygroscopicity parameter $(\mathrm{EH})$, and analytical approximation (AA) models. Detailed information about the used Köhler models can be found in Appendix A. An overview of the tested models and parameterizations is given in Table 3 , and the results are summarized in Figs. 10 and 11. A table of $S_{c}$ vs. $D_{s}$ calculated with the different models is provided in the online supplementary material (http://www.atmos-chem-phys.net/8/1153/ 2008/acp-8-1153-2008-supplement.sip).

\subsubsection{Effects of solution density and surface tension}

For the CCN activation of the salt particles investigated in this study, different parameterizations and approximations of aqueous solution density $\left(\rho_{\text {sol }}\right)$ and surface tension $\left(\sigma_{\text {sol }}\right)$ had only a small influence on the critical supersaturation.
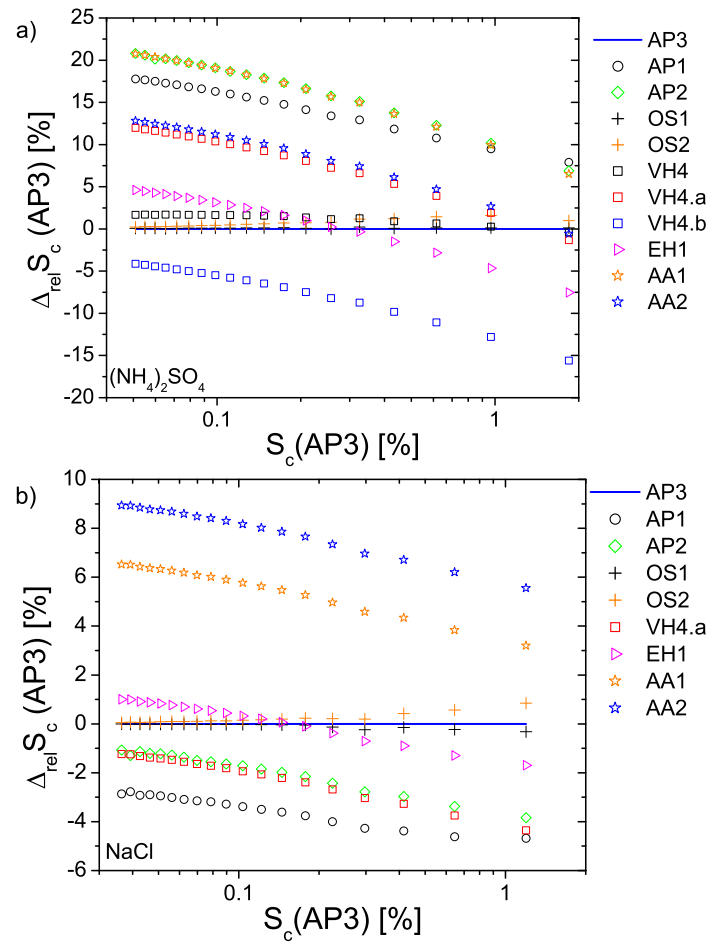

Fig. 11. Relative deviations of $S_{c}$ values calculated with different Köhler models as listed in Table 3 relative to the AP3 model for (a) ammonium sulfate and (b) sodium chloride (298.15 K).

In the AP3 model for ammonium sulfate, $S_{c}$ decreased by less than $0.3 \%$ (relative) when volume additivity was assumed to calculate $\rho_{\text {sol }}$ (AP3.a) instead of using the experimental parameterization of Tang and Munkelwitz (1994). Using the density of pure water to approximate $\rho_{\text {sol }}$ (AP3.b) lowered the supersaturation by up to $\sim 1 \%$ (relative). Approximating $\sigma_{\text {sol }}$ by a temperature-dependent parameterization for pure water (AP3.c) or by a constant value of $0.072 \mathrm{~N} \mathrm{~m}^{-1}$ (AP3.d) reduced $S_{c}$ by up to $1.3 \%$ or $1.8 \%$ (relative), respectively.

The influence of $\rho_{\text {sol }}$ and $\sigma_{\text {sol }}$ on $S_{c}$ was most pronounced for small particle diameters (high solute molalities). For large particles, the approximations of $\rho_{\text {sol }}$ and $\sigma_{\text {sol }}$ had no significant influence on $S_{c}$. Similar results were obtained when using different parameterizations of solution density and surface tension in other types of Köhler models (OS, VH, EH) for ammonium sulfate.

For sodium chloride, the relative deviations in $S_{c}$ caused by different parameterizations of solution density and surface tension were even smaller than for ammonium sulfate. The maximum deviations relative to AP3 were $-0.1 \%$ for AP3.a, $-0.4 \%$ for AP3.b, $-0.6 \%$ for AP3.c, and $-1 \%$ for AP3.d.

Overall, the model deviations caused by different parameterizations and approximations for solution density and surface tension were smaller than the characteristic statistical 
Table 3. Overview of the Köhler models described in Appendix A and compared in Sects. 3.7 and 3.8 (AS=ammonium sulfate; SC=sodium chloride).

\begin{tabular}{|c|c|c|c|c|}
\hline model & Köhler equation & solution density & surface tension & water activity representation \\
\hline \multicolumn{5}{|c|}{ Activity parameterization (AP) models } \\
\hline AP1 & Eq. (A14) & Eq. (A9) & Eq. (A12) & Eq. $(A 7)^{\mathrm{a}, \mathrm{b}}$ \\
\hline AP2 & Eq. (A14) & Eq. (A10) & Eq. (A12) & Eq. $(\mathrm{A} 8)^{\mathrm{c}}$ \\
\hline AP3 & Eq. (A14) & Eq. (A9) & Eq. (A12) & $\mathrm{AIM}^{\mathrm{d}}$ \\
\hline AP3.a & Eq. (A14) & Eq. (A10) & Eq. (A12) & $\mathrm{AIM}^{\mathrm{d}}$ \\
\hline AP3.b & Eq. (A14) & $\rho_{w}$ & Eq. (A12) & $\mathrm{AIM}^{\mathrm{d}}$ \\
\hline AP3.c & Eq. (A14) & Eq. (A9) & $\sigma_{w}$ & $\mathrm{AIM}^{\mathrm{d}}$ \\
\hline AP3.d & Eq. (A14) & Eq. (A9) & $0.072 \mathrm{~N} \mathrm{~m}^{-1}$ & $\mathrm{AIM}^{\mathrm{d}}$ \\
\hline \multicolumn{5}{|c|}{ Osmotic coefficient (OS) models } \\
\hline OS1 & Eq. (A14) & Eq. (A9) & Eq. (A12) & Eq. $(\mathrm{A} 15),(\mathrm{A} 16)^{\mathrm{e}}$ \\
\hline OS2 & Eq. (A14) & Eq. (A9) & Eq. (A12) & Eq. $(A 15),(A 17)^{f}$ \\
\hline \multicolumn{5}{|c|}{ Van't Hoff factor $(\mathrm{VH})$ models } \\
\hline VH1 & Eq. (A14) & Eq. (A9) & Eq. (A12) & Eqs. (A18), (A25) ${ }^{\mathrm{g}},(\mathrm{A} 26)^{\mathrm{h}}$ \\
\hline VH2 & Eq. (A20) & Eq. (A9) & Eq. (A12) & Eqs. $(\mathrm{A} 25)^{\mathrm{g}},(\mathrm{A} 26)^{\mathrm{h}}$ \\
\hline VH3 & Eq. (A21) & Eq. (A9) & Eq. (A12) & Eqs. $(\mathrm{A} 25)^{\mathrm{g}},(\mathrm{A} 26)^{\mathrm{h}}$ \\
\hline VH4 & Eq. (A22) & $\rho_{w}$ & $\sigma_{w}$ & Eqs. $(\mathrm{A} 25)^{\mathrm{g}},(\mathrm{A} 26)^{\mathrm{h}}$ \\
\hline VH4.a & Eq. (A22) & $\rho_{w}$ & $\sigma_{w}$ & $\mathrm{AS}: i_{S}=2.2, \mathrm{SC}: i_{S}=2$ \\
\hline VH4.b & Eq. (A22) & $\rho_{w}$ & $\sigma_{w}$ & $\mathrm{AS}: i_{s}=3$ \\
\hline \multicolumn{5}{|c|}{ Effective hygrosocopicity parameter (EH) model } \\
\hline EH1 & Eq. (A30) & Eq. (A9) & Eq. (A12) & AS: $\kappa=0.61^{\mathrm{i}}, \mathrm{SC}: \kappa=1.28^{\mathrm{i}}$ \\
\hline \multicolumn{5}{|c|}{ Analytical approximation (AA) models } \\
\hline AA1 & Eq. (A31) & $\rho_{w}$ & $\sigma_{w}$ & $\mathrm{AS}: i_{S}=2.2, \mathrm{SC}: i_{S}=2$ \\
\hline AA1.a & Eq. (A31) & $\rho_{w}$ & $\sigma_{w}$ & $\mathrm{AS}: i_{s}=3$ \\
\hline AA2 & Eq. (A32) & $\rho_{w}$ & $\sigma_{w}$ & $\mathrm{AS}: \kappa=0.61^{\mathrm{i}}, \mathrm{SC}: \kappa=1.28^{\mathrm{i}}$ \\
\hline
\end{tabular}

${ }^{\mathrm{a}}$ Tang and Munkelwitz (1994), ${ }^{\mathrm{b}}$ Tang (1996), ${ }^{\mathrm{c}}$ Kreidenweis et al. (2005), ${ }^{\mathrm{d}}$ Clegg et al. (1998a, b), ${ }^{\mathrm{e}}$ Pitzer and Mayorga (1973), ${ }^{\mathrm{f}}$ Brechtel and Kreidenweis (2000), ${ }^{\mathrm{g}}$ Low (1969), ${ }^{\mathrm{h}}$ Young and Warren (1992), ${ }^{\mathrm{i}}$ Petters and Kreidenweis (2007)

uncertainties of field measurements $( \pm 5-7 \%)$. Nevertheless, they can exceed the statistical uncertainty of laboratory experiments $( \pm 1 \%$, see Table 4$)$ and should not be neglected in studies aiming at high accuracy.

\subsubsection{Effects of water activity representation}

According to Clegg and Wexler (2007), the uncertainty of water activity calculations with the Aerosol Inorganics Model (AIM, http://www.aim.env.uea.ac.uk/aim/aim.html; Clegg et al., 1998a, b) for dilute aqueous solutions of ammonium sulfate and sodium chloride is only $10^{-6}-10^{-5}$, and the AIM can be regarded as an accurate reference for the parameterization of water activity in Köhler model calculations.

Figure 11a shows the relative deviations of $S_{c}$ for ammonium sulfate particles calculated with different Köhler models relative to the AIM-based activity parameterization model AP3.

As expected, the results of the osmotic coefficient model OS1 were nearly identical to AP3 (relative deviations $<0.2 \%$ ), because both models are based on similar ioninteraction approaches. The results of the OS2 model, which is based on a simplified ion-interaction approach, were also near-identical at low $S_{c}$ but deviated by up to $+3 \%$ at high $S_{c}$, i.e., for small particles and high solute molality in the droplet with the critical wet particle diameter $\left(D_{s} \approx 20 \mathrm{~nm}\right.$, $\mu_{s} \approx 0.3 \mathrm{~mol} \mathrm{~kg}^{-1}, D_{\text {wet }, c} \approx 75 \mathrm{~nm}$ ).

The results of the van't Hoff factor model VH4 were nearly identical to AP3 at high $S_{c}$, but $\sim 2 \%$ higher at low $S_{c}$, i.e., for large particles and low solute molality in the droplet with the critical wet particle diameter $\left(D_{s}=200 \mathrm{~nm}\right.$, $\mu_{s} \approx 0.006 \mathrm{~mol} \mathrm{~kg}^{-1}, D_{\text {wet }, c} \approx 2.7 \mu \mathrm{m}$ ).

The results of VH1 and VH2 were near-identical to VH4 (rel. dev. $<1 \%$ ), but VH3 was about $2.5 \%$ higher at high $S_{c}$ (not shown in Fig. 11). This deviation of VH3 is due to the simplifying assumption that the contribution of the solute to the total mass of the droplet is negligibly small, which is not really the case for small $D_{s}$ and $D_{\text {wet, } c}$. This simplifying assumption is also made in $\mathrm{VH} 4$, but there it is compensated by approximating the density of the ammonium sulfate solution with the density of water.

The results of the VH4.a model assuming a constant van't Hoff factor $i_{s}=2.2$ were similar to AP3 at high $S_{c}$, but they deviated by up to $+12 \%$ at low $S_{c}$. Model VH4.b assuming $i_{s}=3$ deviated by $-4 \%$ at low $S_{c}$ and by $-16 \%$ at high $S_{c}$. 
The effective hygroscopicity parameter model (EH) deviated from AP3 by $+5 \%$ at low $S_{c}$ and by $-8 \%$ at high $S_{c}$. Note that the constant $\kappa$-value of 0.61 assumed in EH1 is equivalent to a constant van't Hoff factor of 2.52.

The water activity parameterization models AP1 and AP2 yielded much higher $S_{c}$ values than AP3. The relative deviations ranged from $+18 \%$ and $+21 \%$, respectively, at low $S_{c}$ to $+8 \%$ at high $S_{c}$.

The analytical approximation model (AA) with $i_{s}=2.2$ (AA1) was nearly identical to the AP2 model, deviating by $+7 \%$ to $+21 \%$ from AP3. The deviations of AA1.a with $i_{s}=3$ were smaller but still substantial $(-9 \%$ to $+4 \%$ relative from AP3).

Overall, only the models OS1, OS2 and VH1 to VH4 exhibited deviations from AP3 that were smaller than the statistical measurement uncertainty $(\sim 2 \%$, Table 4$)$, and the deviations of the EH1 model were of similar magnitude as the variability of calibrations in field measurement campaigns (up to $\sim 10 \%$, Table 4 ).

Figure 11b shows the relative deviations of $S_{c}$ for sodium chloride particles calculated with different Köhler models relative to the AIM-based activity parameterization model AP3.

Again, the results of the osmotic coefficient model OS1 were nearly identical to AP3 (relative deviations $<0.3 \%$ ), and the OS2 model exhibited substantial deviations only at high $S_{c}$ (up to $+1 \%$ relative). The deviations of the EH1 model did also not exceed the statistical measurement uncertainty of $\sim 2 \%$. The relative deviations of the other tested models ranged from $-5 \%$ for AP1 at high $S_{c}$ to $+7 \%$ for AA1 at low $S_{c}$, which is still less pronounced than the deviations found for $\left(\mathrm{NH}_{4}\right)_{2} \mathrm{SO}_{4}(-16 \%$ to $+21 \%$ rel.).

In any case, the model deviations caused by different parameterizations and approximations of water activity were much larger than the deviations related to solution density and surface tension. Test calculations with the AP3 model showed that deviations of water activity by $10^{-5}\left(10^{-4}\right)$ correspond to relative changes of critical supersaturation on the order of $0.06-2 \%(0.6-20 \%)$ for the investigated dry particle diameter range of 20-200 $\mathrm{nm}$ (largest deviations at large $D_{s}$ and $D_{\text {wet,c }}$ corresponding to low $\mu_{s}$ ).

Provided that the relative uncertainty of water activities calculated with the AIM is indeed as low as $10^{-6}-10^{-5}$, only Köhler models that are based on the AIM (such as AP3) or that yield very similar results (such as OS1, OS2, VH4) should be used for $\mathrm{CCNC}$ calibration and other investigations involving the $\mathrm{CCN}$ activation of $\left(\mathrm{NH}_{4}\right)_{2} \mathrm{SO}_{4}$ and $\mathrm{NaCl}$.

\subsubsection{Temperature effects}

To test the influence of temperature, we have calculated $S_{c}$ for ammonium sulfate particles with the AP3 model not only at $298.15 \mathrm{~K}$ but also at $303.15 \mathrm{~K}$ (and $308.15 \mathrm{~K}$ ). The temperature change had hardly any influence on the AIM-based parameterization of water activity (rel. change of $a_{w}<10^{-5}$ ), but the Kelvin term and $S_{c}$ changed by about $-4 \%$ (relative) for all investigated particle sizes $(-8 \%$ at $308.15 \mathrm{~K})$. Similar results were obtained with the other Köhler models.

The effect of temperature on Köhler model calculations of $S_{c}$ (relative change approx. $-1 \% \mathrm{~K}^{-1}$ ) is of similar magnitude as the experimentally observed and CCNC flow modelderived dependences of $S_{\text {eff }}$ on $T_{1}\left(-0.5 \% \mathrm{~K}^{-1}\right.$ to $-2 \% \mathrm{~K}^{-1}$; Sect. 3.6, Figs. 8a and 9a).

Clearly, the temperature is one of the most important influencing factors not only for the experimental performance of the CCNC (reproducibility of CCN efficiency spectra), but also for the Köhler model calculations used to convert the measured activation diameters into effective water vapor supersaturations.

As outlined in Sect. 2.1, CCN activation is assumed to occur in the first half of the CCNC flow column, where the column temperature increases from $T_{1}$ to $T_{2}\left(T_{2} \approx T_{1}+\Delta T / 2\right)$. Neither the instrument manual nor Roberts and Nenes (2005) or Lance et al. (2006), however, have specified explicitly which temperature should be regarded as the effective temperature to be inserted in Köhler model calculations for instrument calibration. In this study we have taken $T_{1}$, which represents a lower limit for the effective temperature in the CCNC column.

According to the instrument's operating principles, the actual temperature increase along the centerline of the aerosol flow is smaller than the increase of column temperature. Nevertheless, $\Delta T / 2$ can be regarded as an upper limit for deviations of the effective temperature in the CCNC from $T_{1}$. In this study the maximum values of $\Delta T$ and $\Delta T / 2$ were $17 \mathrm{~K}$ and $8.5 \mathrm{~K}$, respectively, which corresponds to a maximum relative deviation (bias) of $S_{\text {eff }}$ by about $-7 \%$. In practice and at lower $\Delta T$, the deviations should be smaller.

3.8 CCN activation of ammonium sulfate and sodium chloride particles: consistency of experimental results and model calculations

To test the consistency of experimental results and model calculations for the $\mathrm{CCN}$ activation of different substances, calibration experiments have been performed with $\left(\mathrm{NH}_{4}\right)_{2} \mathrm{SO}_{4}$ and with $\mathrm{NaCl}$ under near-identical laboratory conditions. Exemplary calibration lines ( $S_{\text {eff }}$ vs. $\Delta T$ ) obtained with the different aerosols and with different Köhler models are shown in Fig. 12.

The $\left(\mathrm{NH}_{4}\right)_{2} \mathrm{SO}_{4}$ and $\mathrm{NaCl}$ calibration lines obtained with the AP3 model $\left(\left(\mathrm{NH}_{4}\right)_{2} \mathrm{SO}_{4}-\mathrm{AP} 3, \mathrm{NaCl}-\mathrm{AP} 3\right)$ and with models yielding similar results for both salts (OS1, OS2, VH4) were in good agreement when no shape correction was applied to the measured $\mathrm{NaCl}$ activation diameters (Fig. 12a; relative deviations $1-3 \%$ at $S_{\text {eff }}>0.3 \%$ ).

If, however, a dynamic shape factor of 1.08 , which is widely used to account for cubic shape of $\mathrm{NaCl}$ particles (e.g., Krämer et al., 2000; Gysel et al., 2002; Mikhailov et al., 2004), was applied to correct the measured $\mathrm{NaCl}$ activation 

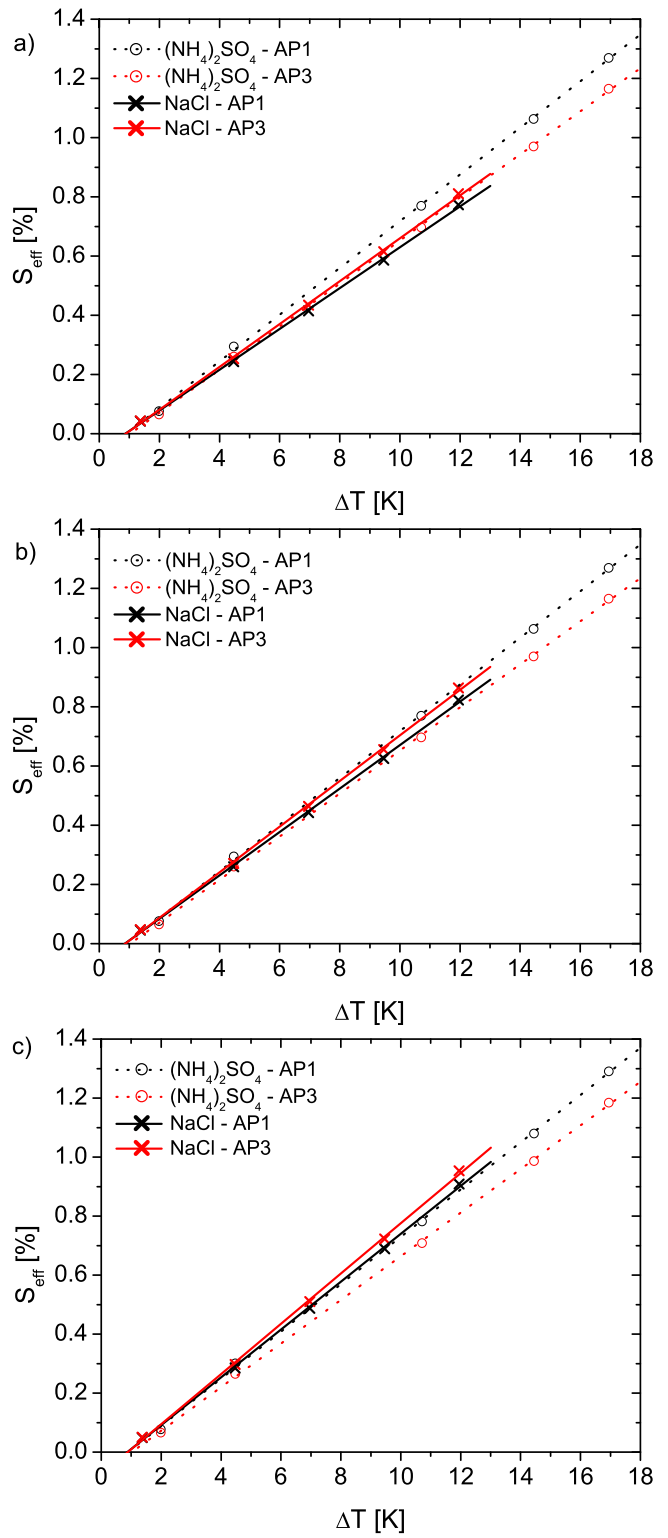

Fig. 12. Calibration lines of effective supersaturation $\left(S_{\text {eff }}\right)$ vs. temperature difference $(\Delta T)$ obtained from experiments with ammonium sulfate and sodium chloride particles under equal conditions $\left(Q=(0.5 \pm 0.001) \mathrm{L} \mathrm{min}^{-1}, \quad p=(999 \pm 6) \mathrm{hPa}, T_{1}=(299.6 \pm 0.05) \mathrm{K}\right)$ : (a) without particle shape correction $(\chi=1.0)$, (b) with $\chi=1.0$ for $\left(\mathrm{NH}_{4}\right)_{2} \mathrm{SO}_{4}$ and $\chi=1.08$ for $\mathrm{NaCl}$, (c) with $\chi=1.02$ for $\left(\mathrm{NH}_{4}\right)_{2} \mathrm{SO}_{4}$ and size dependent $\chi$ (Biskos et al., 2006) for $\mathrm{NaCl}$. The data points were calculated from measured dry particle activation diameters using different Köhler models (AP1, AP3; Table 3); the lines are linear fits.

diameters, the $S_{\text {eff }}$ values of NaCl-AP3 were $7-23 \%$ (relative) higher than those of $\left(\mathrm{NH}_{4}\right)_{2} \mathrm{SO}_{4}$-AP3 (Fig. 12b).

When the shape factors proposed by Biskos et al. (2006) were applied (1.02 for $\left(\mathrm{NH}_{4}\right)_{2} \mathrm{SO}_{4}$, size-dependent factor between 1.08 and 1.24 for $\mathrm{NaCl}$ ), the $S_{\text {eff }}$ values of $\mathrm{NaCl}$ -

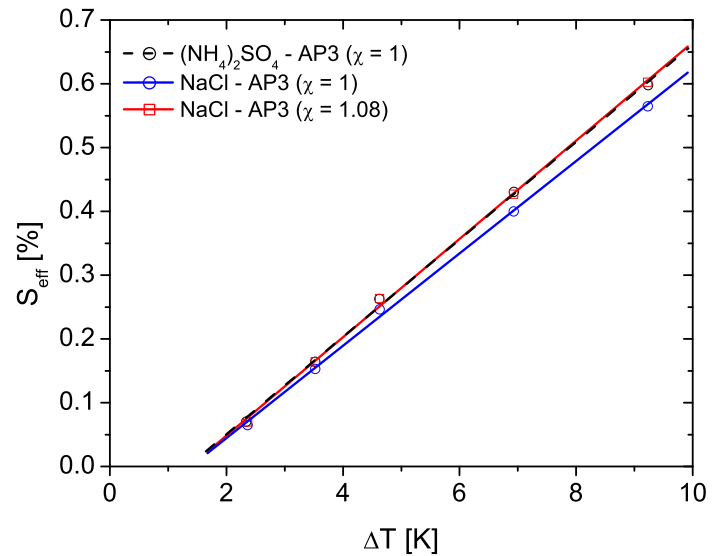

Fig. 13. Calibration lines of effective supersaturation $\left(S_{\text {eff }}\right)$ vs. temperature difference $(\Delta T)$ obtained from experiments with ammonium sulfate and sodium chloride particles under equal conditions $\left(Q=(0.5 \pm 0.001) \mathrm{L} \mathrm{min}^{-1}, p=(998 \pm 3) \mathrm{hPa}, T_{1}=(297.9 \pm 0.5) \mathrm{K}\right) . \mathrm{In}$ these experiments the particles were generated with an alternative method (diffusion drying instead mixing with dry air). The data points were calculated from measured dry particle activation diameters using the AP3 Köhler model; the lines are linear fits.

AP3 were 17-30\% higher than those of $\left(\mathrm{NH}_{4}\right)_{2} \mathrm{SO}_{4}$-AP3 (Fig. 12c). In this case, however, the $\left(\mathrm{NH}_{4}\right)_{2} \mathrm{SO}_{4}$ and $\mathrm{NaCl}$ calibration lines obtained with the AP1 model were in good agreement (relative deviations $\sim 2 \%$ at $S_{\text {eff }}>0.15 \%$ ). Similar results were obtained with AP2.

The changes of $S_{\text {eff }}$ caused by $\mathrm{NaCl}$ particle shape correction $(6-18 \%)$ clearly exceeded the statistical measurement uncertainties of $1-2 \%$. They indicate that the shape and microstructure of calibration aerosol particles can strongly influence the calibration of a CCNC.

Under the assumption that the AIM-based Köhler model AP3 can be regarded as accurate and that there is no artificial bias between the calibration experiments with $\left(\mathrm{NH}_{4}\right)_{2} \mathrm{SO}_{4}$ and with $\mathrm{NaCl}$, the above results indicate that both the $\left(\mathrm{NH}_{4}\right)_{2} \mathrm{SO}_{4}$ and $\mathrm{NaCl}$ particles were more or less compact spheres $(\chi \approx 1)$ or had at least very similar dynamic shape factors. Alternatively, the results would indicate an inconsistency between the AIM-based water activity parameterizations for $\left(\mathrm{NH}_{4}\right)_{2} \mathrm{SO}_{4}$ and $\mathrm{NaCl}$.

Usually, $\mathrm{NaCl}$ aerosol particles generated by nebulization of an aqueous solution are assumed to be of near-cubic shape. Earlier investigations based on HTDMA experiments and electron microscopy, however, had already shown that the shape and microstructure of $\mathrm{NaCl}$ particles depend strongly on the drying conditions and relative humidity to which they are exposed (Mikhailov et al., 2004). NaCl particles generated by nebulization were found to be near-spherical after conditioning at relative humidities close to but below the deliquescence threshold ( $\sim 75 \% \mathrm{RH})$. 
Following up on the interactive public discussion of this manuscript in ACPD (http: //www.atmos-chem-phys-discuss.net/7/8193/2007/ acpd-7-8193-2007.html), we have performed additional test experiments in which we have systematically varied the conditions of aerosol generation. As described in Sect. 2.2, the salt particles for all calibration experiments reported above had been generated by the mixing of nebulized salt solution droplets with an excess of dry air (rapid quenching to $<15 \% \mathrm{RH}$ ). In the additional test experiments, the nebulized salt solution droplets were instead dried with a silica gel diffusion drier (gradual drying to $<5 \% \mathrm{RH}$ ). Under these conditions, the $S_{\text {eff }}$ values obtained from the $\mathrm{NaCl}$ activation diameters with the $\mathrm{NaCl}-\mathrm{AP} 3$ model were $6-7 \%$ lower than those obtained from the $\left(\mathrm{NH}_{4}\right)_{2} \mathrm{SO}_{4}$ activation diameters with the $\left(\mathrm{NH}_{4}\right)_{2} \mathrm{SO}_{4}$-AP3 model. After correction of the $\mathrm{NaCl}$ activation diameters with a shape factor of 1.08, however, the $\left(\mathrm{NH}_{4}\right)_{2} \mathrm{SO}_{4}$ and $\mathrm{NaCl}$ calibration lines obtained with the AP3 model were in good agreement (Fig. 13; relative deviations $<1 \%$ at $S_{\text {eff }}>0.1 \%$ ).

These results support the consistency of the AIM-based water activity parameterizations for dilute aqueous solutions of $\left(\mathrm{NH}_{4}\right)_{2} \mathrm{SO}_{4}$ and $\mathrm{NaCl}$, and they indicate inconsistencies between the widely used parameterizations applied in the Köhler models AP1 and AP2, which are based on the extrapolation of electrodynamic balance (EDB) and hygroscopicity tandem differential mobility analyzer (HTDMA) measurement data (Tang, 1996; Tang and Munkelwitz, 1994; Kreidenweis, 2005). In any case, they demonstrate that the conditions of particle generation and the shape and microstructure of $\mathrm{NaCl}$ particles are critical for their application in $\mathrm{CCN}$ activation and CCNC calibration experiments. Further systematic investigations of the dependence of $\mathrm{NaCl}$ aerosol particle shape and microstructure on particle generation and conditioning are under way and will be presented and discussed in detail elsewhere.

\section{Summary and conclusions}

Table 4 summarizes the $\mathrm{CCNC}$ calibration and measurement uncertainties determined in this study. Under stable operating conditions, the effective water vapor supersaturation $\left(S_{\text {eff }}\right)$ in the DMT-CCNC can be adjusted with high precision. The relative standard deviations of repeated measurements in laboratory experiments were as low as $\pm 1 \%$ for $S_{\text {eff }}>0.1 \%$. During field measurements, however, the relative variability increased to about $\pm 5 \%$, which is mostly due to variations of the CCNC column top temperature $\left(T_{1}\right)$ with ambient temperature.

According to the instrument operating principles, $S_{\text {eff }}$ is controlled not only by the temperature difference between the top and bottom of the flow column $(\Delta T)$, but also by the absolute temperature, pressure $(p)$, and aerosol flow rate $(Q)$. The observed dependence can be described by the following gradients: $\left(\Delta S_{\text {eff }}\right.$ $\left./ S_{\text {eff }}\right) / \Delta T_{1} \approx-2 \% \mathrm{~K}^{-1}$ at $p \approx 1020 \mathrm{hPa}$ and $Q=0.5 \mathrm{~L} \mathrm{~min}^{-1}$; $\left(\Delta S_{\mathrm{eff}} / S_{\mathrm{eff}}\right) / \Delta p \approx+0.1 \% \mathrm{hPa}^{-1}$ at $Q=0.5 \mathrm{~L} \mathrm{~min}^{-1}$ and $T_{1} \approx 299 \mathrm{~K} ;$ and $\left(\Delta S_{\text {eff }} / S_{\text {eff }}\right) / \Delta Q \approx+0.15 \%\left(\mathrm{~mL} \mathrm{~min}^{-1}\right)^{-1}$ at $p \approx 1020 \mathrm{hPa}$ and $T_{1} \approx 299 \mathrm{~K}$.

At high supersaturations $\left(S_{\mathrm{eff}}>0.1 \%\right)$, the experimental data points agreed well with a linear calibration function of $S_{\text {eff }}$ vs. $\Delta T$ (relative deviations $\leq 3 \%$ ). At $S_{\text {eff }}<0.1 \%$, however, the calibration line deviated by up to $\sim 40 \%$ from experimental data points, indicating that in this range $S_{\text {eff }}$ does not linearly depend on $\Delta T$ and special care has to be taken to obtain reliable measurements. Besides careful calibration, it may be beneficial to operate the CCNC at particularly low flow rates $\left(<0.5 \mathrm{~L} \mathrm{~min}^{-1}\right)$ to achieve high precision at low $S_{\text {eff. }}$

After the subtraction of a constant temperature offset and the derivation of an instrument-specific thermal resistance parameter $\left(R_{T} \approx 0.24 \mathrm{~K} \mathrm{~W}^{-1}\right)$, the experimental calibration results could be fairly well reproduced by the CCNC flow model of Lance et al. (2006). At $S_{\text {eff }}>0.1 \%$ the relative deviations between flow model and experimental results were mostly less than $10 \%$. At $S_{\text {eff }} \leq 0.1 \%$, however, the deviations exceeded $40 \%$, which can be attributed to nonidealities which also cause the near-constant temperature offset. Therefore, we suggest that the CCNC flow model can be used for extrapolating the results of experimental calibrations to different operating conditions, but should generally be complemented by calibration experiments performed under the relevant conditions - especially at low $S_{\text {eff }}$.

In the course of several field and laboratory measurement campaigns extending over a period of about one year, we found a systematic decrease of the slope of the calibration line by about $10 \%$ which could not be reversed by standard cleaning procedures and may require a full refurbishing of the instrument to be reversed. In any case, we recommend careful and repeated calibration experiments during every field campaign to ensure reliable operation and to obtain representative uncertainty estimates for the $\mathrm{CCN}$ measurement data.

Besides experimental variabilities, Table 4 also summarizes calibration and measurement uncertainties related to data analysis and Köhler model calculations.

If the influence of doubly charged particles is not taken into account in the fitting of CCN efficiency spectra, the dry particle activation diameter can be underestimated, and the effective supersaturation can be overestimated by up to $\sim 3 \%$. The transfer function of the differential mobility analyzer used to generate monodisperse calibration aerosols affected $S_{\text {eff }}$ by less than $1 \%$ (relative). Moreover, the effective temperature of $\mathrm{CCN}$ activation in the instrument may be higher than the column top temperature $\left(T_{1}\right)$, which was used for Köhler model calculations. This can lead to a bias in $S_{\text {eff }}$ of up to about $-5 \%$. Note that the above percentages refer to the range of operating conditions tested in this study; the uncertainties may change under different experimental conditions. 
Table 4. Overview of characteristic calibration and measurement uncertainties affecting the effective supersaturation in the CCNC (for $S_{\text {eff }}>0.1 \%$ ): statistical uncertainties are characterized by observed relative standard deviations (preceded by " \pm "); systematic errors are characterized by observed/calculated maximum relative deviations (preceded by a sign indicating the direction of bias, if known).

\begin{tabular}{ll}
\hline source of uncertainty/bias & $\begin{array}{l}\text { characteristic relative } \\
\text { deviation of } S_{\text {eff }}(\%)\end{array}$ \\
\hline Measurement precision in single experiment (hours) & \pm 1 \\
Variability of conditions in single field campaign (weeks) & \pm 5 \\
Long-term changes of instrument properties (months) & -10 \\
CCNC flow model extrapolations $\left(T_{1}, p\right)$ & 10 \\
Doubly charged particles & +3 \\
DMA transfer function & $<1$ \\
Effective temperature of CCN activation $\left(T_{1}, T_{2}\right)$ & -5 \\
Solution density approximation & -1 \\
Surface tension approximation & -2 \\
Water activity representation for $\left(\mathrm{NH}_{4}\right)_{2} \mathrm{SO}_{4}$ & -16 to +21 \\
Water activity representation for $\mathrm{NaCl}$ & -5 to +9 \\
Particle shape correction for $\mathrm{NaCl}$ & up to 18 \\
\hline
\end{tabular}

Different ways of calculating or approximating solution density and surface tension in the Köhler models can lead to relative underestimations of $S_{\text {eff }}$ which are small (up to $-1 \%$ and $-2 \%$, respectively), but not negligible with regard to measurement precision under stable operating conditions.

Large deviations were caused by the different parameterizations for the activity of water in dilute aqueous solutions of the two salts (Appendix A), with water activity differences on the order of $\sim 10^{-4}$ corresponding to supersaturation differences on the order of $\sim 10 \%$ (relative). For the relevant range of water vapor supersaturation $(0.05-2 \%)$ and solute molality $\left(\sim 0.003-0.3 \mathrm{~mol} \mathrm{~kg}^{-1}\right)$, the relative deviations from a reference model based on the Aerosol Inorganics Model (AIM) were in the range of $-16 \%$ to $+21 \%$ for $\left(\mathrm{NH}_{4}\right)_{2} \mathrm{SO}_{4}$ and $-5 \%$ to $+9 \%$ for $\mathrm{NaCl}$.

Provided that the AIM can be regarded as an accurate source of water activity data for highly dilute solutions of $\left(\mathrm{NH}_{4}\right)_{2} \mathrm{SO}_{4}$ and $\mathrm{NaCl}$, only Köhler models that are based on the AIM or yield similar results should be used in $\mathrm{CCN}$ studies involving these salts and aiming at high accuracy (Table 3). Concentration-dependent osmotic coefficient models (OS1, OS2) and van't Hoff factor models (VH1-VH4) were found to agree well with the AIM-based model (AP3); models based on widely used water activity parameterizations derived from electrodynamic balance and hygroscopicity tandem differential mobility analyzer measurement data (AP1, AP2), however, deviated strongly. Concentrationindependent van't Hoff factor models (VH4.a, VH4.b), effective hygroscopicity parameter models (EH1), and analytical approximation models (AA1, AA2) generally exhibited a trend from positive deviations at low $S_{\text {eff }}$ to negative deviations at high $S_{\text {eff }}$ (Fig. 11).

In any case, we suggest that CCN studies should always report exactly which Köhler model equations and parameters were used, in order to ensure that the results can be properly compared.

Experiments with $\left(\mathrm{NH}_{4}\right)_{2} \mathrm{SO}_{4}$ and $\mathrm{NaCl}$ aerosols showed that the conditions of particle generation and the shape and microstructure of $\mathrm{NaCl}$ particles are critical for their application in $\mathrm{CCN}$ activation and $\mathrm{CCNC}$ calibration experiments (relative deviations up to $18 \%$ ). The measurement and model results indicate that $\mathrm{NaCl}$ particles generated by nebulization of an aqueous salt solution can change from near-spherical to cubic shape, depending on the drying processes.

\section{Appendix A}

\section{Köhler theory and models}

In this appendix, consistent and precise specifications and distinctions of different types of Köhler models frequently used to calculate critical supersaturations for the CCN activation of ammonium sulfate and sodium chloride aerosol particles will be presented. Model results and differences are compared and discussed in Sects. 3.7 and 3.8.

\section{A1 Basic equations and parameters}

According to Köhler theory (Köhler, 1936; Pruppacher and Klett, 1997; Seinfeld and Pandis, 1998), the condition necessary for an aqueous solution droplet to be in equilibrium with water vapor in the surrounding gas phase can be expressed as follows (Kreidenweis et al., 2005; Koehler et al., 2006):

$s=a_{w} \cdot K e$

The water vapor saturation ratio, $s$, is defined as the ratio of the actual partial pressure of water to the equilibrium vapor 
pressure over a flat surface of pure water at the same temperature. Expressed in percent, $s$ is identical to the relative humidity (RH), which is typically used to describe the abundance of water vapor under sub-saturated conditions. Under supersaturated conditions ( $s>1, \mathrm{RH}>100 \%)$, it is customary to describe the abundance of water vapor by the so-called supersaturation $S$, which is expressed in percent and defined by:

$S=(s-1) \cdot 100 \%$

$a_{w}$ is the activity of water in the aqueous solution, and $K e$ is the so-called Kelvin term, which describes the enhancement of the equilibrium water vapor pressure due to surface curvature.

Under the common assumption that the partial molar volume of water can be approximated by the molar volume of pure water (Kreidenweis et al., 2005), the Kelvin term for a spherical aqueous solution droplet with the diameter $D_{\text {wet }}$ is given by:

$K e=\exp \left(\frac{4 \sigma_{\text {sol }} M_{w}}{R T \rho_{w} D_{\text {wet }}}\right)$

$M_{w}$ and $\rho_{w}$ are the molar mass and density of water (see Table A1), and $\sigma_{\text {sol }}$ is the surface tension of the solution droplet. $R$ and $T$ are the universal gas constant and absolute temperature, respectively. Deviations from this approximation are generally negligible for the dilute aqueous solution droplets formed by hygroscopic salts like ammonium sulfate and sodium chloride at $s \approx 1$ (Brechtel and Kreidenweis, 2000; Kreidenweis et al., 2005). To describe $a_{w}$ and $\sigma_{\text {sol }}$ as a function of droplet composition, various types of equations, parameterizations, and approximations have been proposed and can be used as detailed below.

For a given type and mass of solute (dissolved substance), a plot of $s$ vs. $D_{\text {wet }}$ generally exhibits a maximum in the region where $s>1$ and $S>0$. The saturation ratio and supersaturation at this maximum are the so-called critical saturation $s_{c}$ and critical supersaturation $S_{c}$, respectively, which are associated with the so-called critical droplet diameter, $D_{\text {wet }, c}$. Droplets reaching or exceeding this diameter can freely grow by condensation of water vapor from the supersaturated gas phase and form cloud droplets (Pruppacher and Klett, 1997; Seinfeld and Pandis, 1998).

Aerosol particles consisting of soluble and hygroscopic substances, such as ammonium sulfate and sodium chloride, generally take up water vapor and already form aqueous solution droplets at $s<1$ (hygroscopic growth). The ratio of the droplet diameter, $D_{\text {wet }}$, to the diameter of a compact spherical particle consisting of the dry solute, $D_{s}$ (mass equivalent diameter of the dry solute particle), is defined as the (mass equivalent) growth factor of the dry solute particle, $g_{s}$ :

$g_{s}=\frac{D_{\mathrm{wet}}}{D_{s}}=\left(\frac{\rho_{s}}{x_{s} \rho_{\mathrm{sol}}}\right)^{\frac{1}{3}}$
Table A1. Density and molar mass at $298.15 \mathrm{~K}$ for the investigated compounds.

\begin{tabular}{lccc}
\hline & $\mathrm{H}_{2} \mathrm{O}$ & $\mathrm{NaCl}$ & $\left(\mathrm{NH}_{4}\right)_{2} \mathrm{SO}_{4}$ \\
\hline$\rho\left[\mathrm{kg} \mathrm{m}^{-3}\right]$ & 997.1 & 2165 & 1770 \\
$M\left[\mathrm{~kg} \mathrm{~mol}^{-1}\right]$ & 0.0180153 & 0.0584428 & 0.1321395 \\
\hline
\end{tabular}

$x_{S}$ is the mass fraction of the solute in the droplet, and $\rho_{s}$ is the density of the dry solute (cf. Table A1). Equations (A1), (A3), and (A4) can be used to describe the hygroscopic growth and CCN activation of aerosol particles $\left(D_{\text {wet }}\right.$ as a function of $s$ - or vice versa - for any given value of $D_{s}$ ), if $a_{w}, \rho_{\mathrm{sol}}$, and $\sigma_{\mathrm{sol}}$ are known as a function of droplet composition, which is usually described by the solute mass fraction $x_{s}$, molality $\mu_{s}$, or molarity $c_{s}$.

The molality is defined as the amount of substance (number of moles) of solute, $n_{s}=m_{s} M_{s}^{-1}$, divided by the mass of solvent, i.e., by the mass of water in an aqueous solution, $m_{w}=n_{w} M_{w} . M_{s}$ is the molar mass of the solute (cf. Table A1), $m_{s}$ is the mass of the solute, and $n_{w}$ is the amount of substance (number of moles) of water in the solution.

The molarity is defined as the amount of substance divided by the volume of the solution in units of $\mathrm{mol} \mathrm{L}^{-1}$. Mass fraction, molality, and molarity of the solute are related by:

$$
\begin{aligned}
& \mu_{s}=\frac{x_{s}}{M_{s}\left(1-x_{s}\right)}=\frac{m_{s}}{M_{s} m_{w}}=\frac{n_{s}}{M_{w} n_{w}}=\frac{\pi \rho_{s} D_{s}^{3}}{6 M_{s} n_{w} M_{w}} \\
& c_{s}=\frac{x_{s} \rho_{\mathrm{sol}}}{M_{s}} \cdot 10^{-3} \mathrm{~m}^{3} \mathrm{~L}^{-1}
\end{aligned}
$$

The scaling factor $10^{-3} \mathrm{~m}^{3} \mathrm{~L}^{-1}$ is required to relate the molarity in $\mathrm{mol} \mathrm{L}^{-1}$ to the other quantities, which are generally given in SI units.

Depending on the types of parameterizations used to describe $a_{w}, \rho_{\text {sol }}$, and $\sigma_{\text {sol }}$, different models can be used to calculate the critical supersaturation $S_{c}$ for any given value of $D_{s}$. The different options considered and compared in this study are outlined below and discussed in Sect. 3.7.

In the Köhler model calculations used for CCNC calibration, the experimentally determined critical dry particle diameter $D_{c}$ (i.e., the fit parameter $D_{a}$, or a shape corrected value as detailed in Sect. 2.3.1.4) was taken as the dry solute mass equivalent diameter $D_{s}$, corresponding to a solute mass of $m_{s}=\pi / 6 \rho_{s} D_{s}^{3}$. The CCNC column top temperature $\left(T_{1}\right)$ was taken as the model temperature $T$.

\section{A2 Activity parameterization (AP) models}

For the activity of water in aqueous solution droplets of $\left(\mathrm{NH}_{4}\right)_{2} \mathrm{SO}_{4}, \mathrm{NaCl}$, and other salts, Tang and Munkelwitz (1994) and Tang (1996) have presented parameterizations derived from electrodynamic balance (EDB) single particle 
Table A2. Polynomial coefficients used to calculate the water activity with Eq. (A7) or (A8). The coefficients $a_{1}, a_{2}, a_{3}$, and $a_{4}$ for $\left(\mathrm{NH}_{4}\right)_{2} \mathrm{SO}_{4}$ and $\mathrm{NaCl}$ at $298 \mathrm{~K}$ are given in Tang and Munkelwitz (1994) and in Tang (1996), respectively. The coefficients $k_{1}, k_{2}$, and $k_{3}$ are the Kelvin corrected values for $\left(\mathrm{NH}_{4}\right)_{2} \mathrm{SO}_{4}$ and the Kelvin and shape corrected values for $\mathrm{NaCl}$, taken from Kreidenweis et al. (2005).

\begin{tabular}{lcc}
\hline $\begin{array}{l}\text { water activity } \\
\text { parameters }\end{array}$ & $\left(\mathrm{NH}_{4}\right)_{2} \mathrm{SO}_{4}$ & $\mathrm{NaCl}$ \\
\hline$a_{1}\left[\mathrm{~kg} \mathrm{~mol}^{-1}\right]$ & $-2.715 \times 10^{-3}$ & $-6.366 \times 10^{-3}$ \\
$a_{2}\left[\mathrm{~kg}^{2} \mathrm{~mol}^{-2}\right]$ & $3.113 \times 10^{-5}$ & $8.624 \times 10^{-5}$ \\
$a_{3}\left[\mathrm{~kg}^{3} \mathrm{~mol}^{-3}\right]$ & $-2.336 \times 10^{-6}$ & $-1.158 \times 10^{-5}$ \\
$a_{4}\left[\mathrm{~kg}^{4} \mathrm{~mol}^{-4}\right]$ & $1.412 \times 10^{-8}$ & $1.518 \times 10^{-7}$ \\
$k_{1}$ & 2.42848 & 5.78874 \\
$k_{2}$ & -3.85261 & -8.38172 \\
$k_{3}$ & 1.88159 & 3.9265 \\
\hline
\end{tabular}

experiments as polynomial fit functions of solute mass percentage $\left(100 x_{s}\right)$ :

$a_{w}=1+\sum_{q} a_{q}\left(100 x_{s}\right)^{q}$

The polynomial coefficients $a_{q}$ for $\left(\mathrm{NH}_{4}\right)_{2} \mathrm{SO}_{4}$ and $\mathrm{NaCl}$ at $298 \mathrm{~K}$ are listed in Table A2.

An alternative parameterization of $a_{w}$ has been proposed by Kreidenweis et al. (2005), who derived the following relation between $a_{w}$ and the growth factor of dry solute particles $\left(g_{s}\right)$ determined in measurements with a hygroscopicity tandem differential mobility analyzer (HTDMA):

$g_{s}=\frac{D_{\mathrm{wet}}}{D_{s}}=\left(1+\left(k_{1}+k_{2} a_{w}+k_{3} a_{w}^{2}\right) \frac{a_{w}}{1-a_{w}}\right)^{\frac{1}{3}}$

The coefficients $k_{1}, k_{2}$, and $k_{3}$ for $\left(\mathrm{NH}_{4}\right)_{2} \mathrm{SO}_{4}$ and $\mathrm{NaCl}$ are listed in Table A2.

The water activity $a_{w}$ can be also calculated with the Aerosol Inorganics Model (AIM, Pitzer-Simonson-Clegg mole fraction based model; http://www.aim.env.uea.ac.uk/ aim/aim.html; Clegg et al., 1998a, b). For a variety of inorganic substances, the solute molality can be calculated online for prescribed $a_{w}$ values and the results can be downloaded in form of a table. We ran the model for $\left(\mathrm{NH}_{4}\right)_{2} \mathrm{SO}_{4}$ and $\mathrm{NaCl}$ at $298.15 \mathrm{~K}$ and obtained for each salt a table of $a_{w}$ vs. $\mu_{s}$ in the activity range of 0.9 to 0.9999 (100 equidistant steps from 0.9 to $0.97,300$ steps of 0.0001 from 0.97 to 0.9999 ), covering a molality range of $\sim 3$ to $\sim 0.002 \mathrm{~mol} \mathrm{~kg}^{-1}$. The used AIM output data are given in the online supplementary material (http://www.atmos-chem-phys.net/8/1153/ 2008/acp-8-1153-2008-supplement.zip).

Low (1969) provided a table of $a_{w}$ for ammonium sulfate and sodium chloride for molality values of 0.1 to $6 \mathrm{~mol} \mathrm{~kg}-1$. For the calculation of $S_{c}$, however, this range of molalities is insufficient and has to be extrapolated below $0.1 \mathrm{~mol} \mathrm{~kg}^{-1}$.
Table A3. Polynomial coefficients used to calculate the density of a solution droplet using Eq. (A9). The coefficients $d_{1}, d_{2}, d_{3}$, and $d_{4}$ for $\left(\mathrm{NH}_{4}\right)_{2} \mathrm{SO}_{4}$ and $\mathrm{NaCl}$ at $298 \mathrm{~K}$ are given in Tang and Munkelwitz (1994) and in Tang (1996), respectively.

\begin{tabular}{lcc}
\hline $\begin{array}{l}\text { density } \\
\text { parameters }\end{array}$ & $\left(\mathrm{NH}_{4}\right)_{2} \mathrm{SO}_{4}$ & $\mathrm{NaCl}$ \\
\hline$d_{1}\left[\mathrm{~kg} \mathrm{~mol}^{-1}\right]$ & $5.92 \times 10^{-3}$ & $7.41 \times 10^{-3}$ \\
$d_{2}\left[\mathrm{~kg}^{2} \mathrm{~mol}^{-2}\right]$ & $-5.036 \times 10^{-6}$ & $-3.741 \times 10^{-5}$ \\
$d_{3}\left[\mathrm{~kg}^{3} \mathrm{~mol}^{-3}\right]$ & $1.024 \times 10^{-8}$ & $2.252 \times 10^{-6}$ \\
$d_{4}\left[\mathrm{~kg}^{4} \mathrm{~mol}^{-4}\right]$ & - & $-2.06 \times 10^{-8}$ \\
\hline
\end{tabular}

We have tested this approach with a third order polynomial fit, but the results were very different from the parameterizations given above (deviations up to a factor of 2 in $S_{c}$ ) and are not discussed any further.

For the density of aqueous solution droplets of $\left(\mathrm{NH}_{4}\right)_{2} \mathrm{SO}_{4}$ and $\mathrm{NaCl}$, and other salts, Tang and Munkelwitz (1994) and Tang (1996) have also presented parameterizations of experimentally determined values as polynomial fit functions of solute mass percentage $\left(100 x_{s}\right)$ :

$\rho_{\mathrm{sol}}=\rho_{w}+\left[\sum_{q} d_{q}\left(100 x_{s}\right)^{q}\right] \cdot 10^{3} \mathrm{~kg} \mathrm{~m}^{-3}$

$\rho_{w}$ is the density of pure water in $\mathrm{kg} \mathrm{m}^{-3}$ (e.g., $997.1 \mathrm{~kg} \mathrm{~m}^{-3}$ at $298 \mathrm{~K})$ and the coefficients for $\left(\mathrm{NH}_{4}\right)_{2} \mathrm{SO}_{4}$ and $\mathrm{NaCl}$ at $298 \mathrm{~K}$ are listed in Table A3.

Under the assumption of volume additivity (partial molar volumes of solute and solvent in solution are equal to molar volumes of pure substances; Mikhailov et al., 2004), $\rho_{\text {sol }}$ can also be calculated by

$\rho_{\text {sol }}=\left(\frac{1-x_{s}}{\rho_{w}}+\frac{x_{s}}{\rho_{s}}\right)^{-1}$

The simplest parameterization of $\rho_{\text {sol }}$ used in this study was approximating it by the density of pure water, either with a constant value of $997.1 \mathrm{~kg} \mathrm{~m}^{-3}$ or a temperature dependent one. The temperature dependence of the density of pure water can be described according to Pruppacher and Klett (1997):

$\rho_{w}=\frac{A_{0}+A_{1} t+A_{2} t^{2}+A_{3} t^{3}+A_{4} t^{4}+A_{5} t^{5}}{1+B t}$

Here $t$ is the temperature in ${ }^{\circ} \mathrm{C}(t=T-273.15 \mathrm{~K})$ and the coefficients $A_{0}$ to $A_{5}$, and $B$ are given in Table A4.

The deviations caused by using different parameterizations and approximations of $\rho_{\text {sol }}$ turned out to be small, as detailed in Sect. 3.7.

For the surface tension of aqueous salt solution droplets, Seinfeld and Pandis (1998) proposed the following parameterization:

$\sigma_{\mathrm{sol}}=\sigma_{w}+\gamma_{s} \cdot c_{s}$ 
in which $\gamma_{s}=2.17 \times 10^{-3} \mathrm{~N} \mathrm{~m}^{-1} \mathrm{~L} \mathrm{~mol}^{-1}$ for $\left(\mathrm{NH}_{4}\right)_{2} \mathrm{SO}_{4}$ and $\gamma_{s}=1.62 \times 10^{-3} \mathrm{~N} \mathrm{~m}^{-1} \mathrm{~L} \mathrm{~mol}^{-1}$ for $\mathrm{NaCl} . \sigma_{w}$ is the surface tension of pure water as detailed below, and $c_{s}$ is the molarity of the solute. Alternative concentration-dependent parameterizations (Hänel, 1976; Weast and Astle, 1982; Chen, 1994; Gysel et al., 2002) exhibited only small deviations in $\sigma_{\mathrm{sol}}$ in the concentration range of interest $(<1 \%$ for $\mu_{s}<1 \mathrm{~mol} \mathrm{~kg}^{-1}$ ).

The simplest parameterization of $\sigma_{\text {sol }}$ used in this study was approximating it by the surface tension of pure water, either with a constant value of $0.072 \mathrm{~N} \mathrm{~m}^{-1}$ or a temperature dependent one. According to Seinfeld and Pandis (1998), the temperature dependence of the surface tension of pure water can be described by:

$\sigma_{w}=0.0761 \mathrm{~N} \mathrm{~m}^{-1}-\gamma_{t}(T-273 \mathrm{~K})$

in which $\gamma_{t}=1.55 \times 10^{-4} \mathrm{~N} \mathrm{~m}^{-1} \mathrm{~K}^{-1}$.

Combination of Eqs. (A1), (A3), and (A4) leads to the following version of the Köhler equation, which was taken as the basis for all activity parameterization (AP) model calculations:

$s=a_{w} \exp \left(\frac{4 \sigma_{\mathrm{sol}} M_{w}}{\rho_{w} R T g_{s} D_{s}}\right)$

Depending on the applied type of water activity parameterization, we distinguish three types of AP models: AP1 using the mass percentage-based parameterizations of Tang and Munkelwitz (1994) and Tang (1996), AP2 using the growth factor-based parameterizations of Kreidenweis et al. (2005), and AP3 using the Pitzer-Simonson-Clegg mole fraction based model AIM.

In AP1 model calculations, $x_{s}$ was taken as the primary variable to calculate $a_{w}$ from Eq. (A7); $\rho_{\text {sol }}$ from Eq. (A9) with $\rho_{w}$ from Eq. (A11); $g_{s}$ from Eq. (A4); $\sigma_{\text {sol }}$ from Eq. (A12) with $\sigma_{w}$ from Eq. (A13) and $c_{s}$ from Eq. (A6); and $s$ from Eq. (A14) (base case AP1, Table 3). The maximum value of $s$ (critical saturation ratio, $s_{c}$ ) was determined by the variation of $x_{s}$ (numerical minimum search for $-s$ with the "fminsearch" function, Matlab software), and via Eq. (A2) it was converted into the corresponding critical supersaturation $S_{c}$.

In AP2 model calculations, $a_{w}$ was taken as the primary variable to calculate $g_{s}$ from Eq. (A8); $\rho_{\text {sol }}$ from Eq. (A10) with $\rho_{w}$ from Eq. (A11); $x_{s}=m_{s} /\left(m_{s}+m_{w}\right)$, and $m_{w}=\pi / 6 \rho_{w} D_{s}^{3}\left(g_{s}^{3}-1\right)$ (volume additivity assumption); $\sigma_{\text {sol }}$ from Eq. (A12) with $\sigma_{w}$ from Eq. (A13) and $c_{s}$ from Eq. (A6); and $s$ from Eq. (A14) (base case AP2, Table 3). The maximum value of $s$ (critical saturation ratio) was determined by variation of $a_{w}$ (numerical minimum search for $-s$ with the 'fminsearch' function, Matlab software), and via Eq. (A2) it was converted into the corresponding $S_{c}$.

In AP3 model calculations, $x_{s}$ was taken as the primary variable to calculate $\mu_{s}$ from Eq. (A5) and $a_{w}$ by linear interpolation of the tabulated data of $a_{w}$ vs. $\mu_{s}$ obtained from the online AIM (see above); $\rho_{\text {sol }}$ from Eq. (A9) with $\rho_{w}$ from
Table A4. Coefficients used to calculate the density of water as a function of temperature according to Eq. (A11) taken from Pruppacher and Klett (1997).

\begin{tabular}{lc}
\hline density parameters & value \\
\hline$A_{0}\left[\mathrm{~kg} \mathrm{~m}^{-3}\right]$ & 999.8396 \\
$A_{1}\left[\mathrm{~kg} \mathrm{~m}^{-3}{ }^{\circ} \mathrm{C}^{-1}\right]$ & 18.224944 \\
$A_{2}\left[\mathrm{~kg} \mathrm{~m}^{-3}{ }^{\circ} \mathrm{C}^{-2}\right]$ & $-7.92221 \times 10^{-3}$ \\
$A_{3}\left[\mathrm{~kg} \mathrm{~m}^{-3}{ }^{\circ} \mathrm{C}^{-3}\right]$ & $-55.44846 \times 10^{-6}$ \\
$A_{4}\left[\mathrm{~kg} \mathrm{~m}^{-3}{ }^{\circ} \mathrm{C}^{-4}\right]$ & $149.7562 \times 10^{-9}$ \\
$A_{5}\left[\mathrm{~kg} \mathrm{~m}^{-3}{ }^{\circ} \mathrm{C}^{-5}\right]$ & $-393.2952 \times 10^{-12}$ \\
$B\left[{ }^{\circ} \mathrm{C}^{-1}\right]$ & $18.159725 \times 10^{-3}$ \\
\hline
\end{tabular}

Eq. (A11); $g_{s}$ from Eq. (A4); $\sigma_{\text {sol }}$ from Eq. (A12) with $\sigma_{w}$ from Eq. (A13) and $c_{s}$ from Eq. (A6); and $s$ from Eq. (A14) (base case AP3, Table 3). The maximum value of $s$ (critical saturation ratio, $s_{c}$ ) was determined by the variation of $x_{s}$ (numerical minimum search for $-s$ with the 'fminsearch' function, Matlab software), and via Eq. (A2) it was converted into the corresponding critical supersaturation $S_{c}$. In sensitivity studies investigating the influence of various simplifications and approximations of the droplet density and surface tension, individual parameterizations were exchanged as detailed in Table 3, but the basic calculation procedure remained unchanged (test cases AP3.a to AP3.d).

\section{A3 Osmotic coefficient (OS) models}

According to Robinson and Stokes (1959), the activity of water in aqueous solutions of ionic compounds can be described by:

$a_{w}=\exp \left(-v_{s} \Phi_{s} \mu_{s} M_{w}\right)$

$v_{s}$ is the stoichiometric dissociation number of the solute, i.e., the number of ions per molecule or formula unit

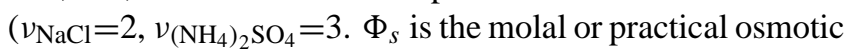
coefficient of the solute in aqueous solution, which deviates from unity if the solution is not ideal (incomplete dissociation, ion-ion and ion-solvent interactions).

Based on an ion-interaction approach, Pitzer and Mayorga (1973) derived semiempirical parameterizations, which describe $\Phi_{s}$ as a function of solute molality $\mu_{s}$. The general form for electrolytes dissociating into two types of ions is:

$$
\begin{aligned}
\Phi_{s} & =1-\left|z_{1} z_{2}\right|\left(A_{\Phi} \frac{\sqrt{I}}{1+b \sqrt{I}}\right) \\
& +\mu_{s} \frac{2 v_{1} v_{2}}{v_{s}}\left(\beta_{0}+\beta_{1} e^{-\alpha \sqrt{I}}\right)+\mu_{s}^{2} \frac{2\left(v_{1} v_{2}\right)^{\frac{3}{2}}}{v_{s}} C_{\Phi}
\end{aligned}
$$

$\nu_{1}$ and $\nu_{2}$ are the numbers of positive and negative ions produced upon dissociation per formula unit of the solute $\left(v_{s}=v_{1}+v_{2}\right) ; \quad\left|z_{1}\right|$ and $\left|z_{2}\right|$ are the numbers of elementary charges carried by the ions: $v_{1}=\left|z_{2}\right|=2$ and 
Table A5. Ion-interaction coefficients at $298.15 \mathrm{~K}$ used to calculate the practical osmotic coefficients of ammonium sulfate and sodium chloride in aqueous solution using Eq. (A16).

\begin{tabular}{llll}
\hline parameter & $\left(\mathrm{NH}_{4}\right)_{2} \mathrm{SO}_{4}{ }^{\mathrm{a}}$ & $\mathrm{NaCl}^{\mathrm{a}}$ & $\mathrm{NaCl}^{\mathrm{b}}$ \\
\hline$\beta_{0}\left[\mathrm{~kg} \mathrm{~mol}^{-1}\right]$ & 0.0409 & 0.0765 & 0.1018 \\
$\beta_{1}\left[\mathrm{~kg} \mathrm{~mol}^{-1}\right]$ & 0.6585 & 0.2664 & 0.2770 \\
$C_{\Phi}\left[\mathrm{kg}^{2} \mathrm{~mol}^{-2}\right]$ & -0.0012 & 0.00127 & 0.00119 \\
\hline
\end{tabular}

a Pitzer and Mayorga (1973); ${ }^{b}$ Mokbel et al. (1997)

Table A6. Parameters of $Y_{a}, Y_{b}$, and $Y_{c}$ for ammonium sulfate and sodium chloride taken from Brechtel and Kreidenweis (2000) used in Eq. (A17).

\begin{tabular}{llll}
\hline Salt & $Y_{a}\left[\mathrm{~mol} \mathrm{~m}^{-3}\right]$ & $Y_{b}\left[\mathrm{~mol} \mathrm{~m}^{-3}\right]$ & $Y_{c}\left[\mathrm{~mol} \mathrm{~m}^{-3}\right]$ \\
\hline$\left(\mathrm{NH}_{4}\right)_{2} \mathrm{SO}_{4}$ & $321.3 \times 10^{-3}$ & $80.3 \times 10^{-3}$ & $8.93 \times 10^{-3}$ \\
$\mathrm{NaCl}$ & $74.1 \times 10^{-3}$ & $74.1 \times 10^{-3}$ & $18.52 \times 10^{-3}$ \\
\hline
\end{tabular}

$v_{2}=\left|z_{1}\right|=1$ for $\left(\mathrm{NH}_{4}\right)_{2} \mathrm{SO}_{4} ; \quad v_{1}=v_{2}=\left|z_{1}\right|=\left|z_{2}\right|=1$ for $\mathrm{NaCl}$. The ionic strength is given by $I=0.5 \mu_{s}\left(v_{1} z_{1}^{2}+v_{2} z_{2}^{2}\right)$. $A_{\Phi}$ is the Debye-Hückel coefficient which has the value $0.3915\left(\mathrm{~kg} \mathrm{~mol}^{-1}\right)^{1 / 2}$ for water at $298.15 \mathrm{~K}$. The parameters $\alpha$ and $b$ are $2\left(\mathrm{~kg} \mathrm{~mol}^{-1}\right)^{1 / 2}$ and $1.2\left(\mathrm{~kg} \mathrm{~mol}^{-1}\right)^{1 / 2}$, respectively. The coefficients $\beta_{0}, \beta_{1}$ and $C_{\Phi}$ depend on the chemical composition of the solute and have been tabulated by Pitzer and Mayorga (1973) for over 200 compounds (1:1, 1:2, and 2:1 electrolytes). For ammonium sulfate and sodium chloride, at $298.15 \mathrm{~K}$, the respective values and more recent updates from Mokbel et al. (1997) are listed in Table A5. In our model calculations we used the parameters of Pitzer and Mayorga (1973). For the relevant conditions of CCN activation, the parameters of Mokbel et al. (1997) lead essentially to the same $S_{c}$ values (relative deviations $<0.4 \%$ ).

A more simplified form of Eq. (A16) was introduced by Brechtel and Kreidenweis (2000):

$\Phi_{s}=1-\frac{A_{\Phi} \sqrt{Y_{a} c}}{\sqrt{2}+b \sqrt{Y_{b} c}}+2 Y_{c} c \beta_{0}$

with the coefficient $c=D_{s}^{3} /\left(\rho_{w}\left(D_{\text {wet }}^{3}-D_{s}^{3}\right)\right)$. The parameters $A_{\Phi}, b$, and $\beta_{0}$ are the same variables used in Eq. (A16) and are given above. The coefficients $Y_{a}, Y_{b}$, and $Y_{c}$ for ammonium sulfate and sodium chloride are taken from Brechtel and Kreidenweis (2000) and listed in Table A6.

Depending on the applied type of osmotic coefficient parameterization, we distinguish two types of OS models: OS1 using the parameterization of Pitzer and Mayorga (1973) (Eq. A16), and OS2 using the parameterization of Brechtel and Kreidenweis (2000) (Eq. A17).
The OS1 model calculations were performed in analogy to the AP1 model calculations as detailed above (with $x_{s}$ as the primary variable for the calculation of other parameters), except that $a_{w}$ was calculated from Eq. (A15) with $\Phi_{s}$ from Eq. (A16) and $\mu_{s}$ from Eq. (A5). The OS2 model calculations were done in the same way as OS1 unless using Eq. (A17) for parameterizing $\Phi_{s}$.

\section{A4 Van't Hoff factor $(\mathrm{VH})$ models}

According to McDonald (1953) and the early cloud physics literature, the activity of water in aqueous solutions of ionic compounds can be described by the following form of Raoult's law, where the effects of ion dissociation and interactions are represented by the so-called van't Hoff factor, $i_{s}$ :

$a_{w}=\frac{n_{w}}{n_{w}+i_{s} n_{s}}=\left(1+i_{s} \frac{n_{s}}{n_{w}}\right)^{-1}=\left(1+i_{s} \mu_{s} M_{w}\right)^{-1}$

For strong electrolytes such as ammonium sulfate and sodium chloride, the van't Hoff factor is similar to the stoichiometric dissociation number, and deviations of $i_{s}$ from $v_{s}$ can be attributed to solution non-idealities (incomplete dissociation, ion-ion and ion-solvent interactions). The exact relation between $i_{s}$ and $v_{s}$ or $\Phi_{s}$ is given by equating Eqs. (A15) and (A18). As detailed by Kreidenweis et al. (2005), the resulting equation can be approximated by a series expansion of the exponential term in Eq. (A15), inserting $n_{s} / n_{w}=\mu_{s} M_{w}$ (cf. Eq. A5) and truncation of the series. It follows then that:

$i_{s} \approx v_{s} \Phi_{s}$

Deviations from this approximation are negligible for the dilute aqueous solution droplets formed by hygroscopic salts such as ammonium sulfate and sodium chloride at $s \approx 1$ (molality $<0.01 \mathrm{~mol} \mathrm{~kg}^{-1}$; relative magnitude of quadratic and higher terms of series expansion $<1 \%$ ).

Combination of Eqs. (A14) and (A15) with $\mu_{s}=m_{s} /\left(M_{s} m_{w}\right), \quad m_{w}=\pi / 6 D_{\mathrm{wet}}^{3} \rho_{\mathrm{sol}}-m_{s}, \quad g_{s} D_{s}=D_{\mathrm{wet}}$, and Eq. (A19) leads to:

$s=\exp \left(\frac{4 \sigma_{\mathrm{sol}} M_{w}}{\rho_{w} R T D_{\mathrm{wet}}}-\frac{i_{s} m_{s} M_{w}}{M_{s}\left(\frac{\pi}{6} D_{\mathrm{wet}}^{3} \rho_{\mathrm{sol}}-m_{s}\right)}\right)$

For the dilute aqueous solution droplets formed by hygroscopic salts like ammonium sulfate and sodium chloride at $s \approx 1$, the contribution of the solute to the total mass of the droplet is low $\left(m_{s} /\left(\pi / 6 D_{\text {wet }}^{3} \rho_{\text {sol }}\right)<4 \%\right.$ at $D_{s}=20 \mathrm{~nm}$ and $<0.1 \%$ at $200 \mathrm{~nm}$ ). If $m_{s}$ is neglected, Eq. (A20) reduces to:

$s=\exp \left(\frac{4 \sigma_{\mathrm{sol}} M_{w}}{\rho_{w} R T D_{\mathrm{wet}}}-\frac{6 i_{s} m_{s} M_{w}}{\pi M_{s} D_{\mathrm{wet}}^{3} \rho_{\text {sol }}}\right)$

For the dilute salt solution droplets, differences between $\rho_{w}$ and $\rho_{\text {sol }}\left(<3 \%\right.$ at $D_{s}=20 \mathrm{~nm},<0.1 \%$ at $\left.200 \mathrm{~nm}\right)$ and between $\sigma_{w}$ and $\sigma_{\text {sol }}\left(<1 \%\right.$ at $D_{s}=20 \mathrm{~nm}, \sim 0 \%$ at $\left.200 \mathrm{~nm}\right)$ are also 
relatively small. With the approximations of $\rho_{\text {sol }} \approx \rho_{w}$ and $\sigma_{\text {sol }} \approx \sigma_{w}$, Eq. (A21) can be transformed into the following simplified and widely used form of the Köhler equation (e.g., Pruppacher and Klett, 1997; Seinfeld and Pandis, 1998):

$s=\exp \left(\frac{A}{D_{\text {wet }}}-\frac{B}{D_{\text {wet }}^{3}}\right)$

where

$A=\frac{4 \sigma_{w} M_{w}}{\rho_{w} R T}$

and

$B=\frac{6 i_{s} m_{s} M_{w}}{\pi M_{s} \rho_{w}}=\frac{i_{s} M_{w} \rho_{s} D_{s}^{3}}{M_{s} \rho_{w}}=\frac{6 i_{s} n_{s} M_{w}}{\pi \rho_{w}}$

Under the assumption of complete dissociation and ideal solution behavior $\left(\Phi_{s}=1\right)$, the van't Hoff factor is $i_{s}=2$ for $\mathrm{NaCl}$ and $i_{s}=3$ for $\left(\mathrm{NH}_{4}\right)_{2} \mathrm{SO}_{4}$ solutions. For $\mathrm{NaCl}$ this approximation is quite common and the deviations from experimental results are small (Gerber et al., 1977), but for $\left(\mathrm{NH}_{4}\right)_{2} \mathrm{SO}_{4}$ it has been shown that $i_{s}$ has to be between 2 and 2.5 to achieve agreement between measured and calculated droplet diameters (Gerber et al., 1977; Pradeep Kumar et al., 2003).

McDonald (1953) already remarked that the van't Hoff factor is not a constant value, but varies with the solute molality. Low (1969) presented a table of van't Hoff factors for a number of electrolytes at molalities of $0.1-6 \mathrm{~mol} \mathrm{~kg}^{-1}$ and $298.15 \mathrm{~K}$. For ammonium sulfate, $i_{s}$ can be parameterized as a function of $\mu_{s}$ with the following cubic polynomial fit of the tabulated values (Frank et al., 2007):

$i_{s}=0.021 \mathrm{~kg}^{2} \mathrm{~mol}^{-2} \cdot \mu_{s}^{2}-0.0428 \mathrm{~kg} \mathrm{~mol}^{-1} \cdot \mu_{s}+1.9478$

An alternative parameterization given by Young and Warren (1992) is valid for smaller molalities:

$$
\begin{aligned}
i_{s}= & -0.007931 \cdot \log ^{2}\left(\mu_{s} \cdot \mathrm{kg} \mathrm{mol}^{-1}\right) \\
& -0.1844 \cdot \log \left(\mu_{s} \cdot \mathrm{kg} \mathrm{mol}^{-1}\right)+1.9242
\end{aligned}
$$

From the different Köhler equations listed above, four different VH models (VH1-VH4) were derived and tested.

The non-simplified VH model calculations (VH1) for ammonium sulfate solution droplets were made taking $\mu_{s}$ as the primary variable to calculate $a_{w}$ from Eq. (A18) and to calculate $i_{s}$. The value of $i_{s}$ was calculated from Eq. (A25) for $\mu_{s}>1$, and from Eq. (A26) for $\mu_{s} \leq 1$ as suggested by Frank et al. (2007). $x_{s}=m_{s} /\left(m_{s}+m_{w}\right) ; m_{w}$ was calculated from Eq. (A5); $\rho_{\text {sol }}$ from Eq. (A9) with $\rho_{w}$ from Eq. (A11); $g_{s}$ from Eq. (A4); $\sigma_{\text {sol }}$ from Eq. (A12) with $\sigma_{w}$ from Eq. (A13) and $c_{s}$ from Eq. (A6); and $s$ from Eq. (A14).

VH2 model calculations were made using a simplified Köhler equation (Eq. A20; assuming $i_{s} \approx v_{s} \Phi_{s}$ ). In this equation, $i_{s}$ was calculated as in VH1 using $\mu_{s}$ as a primary variable. $x_{s}, \rho_{w}, \rho_{\text {sol }}$, and $\sigma_{\text {sol }}$ were calculated as in VH1. $D_{\text {wet }}$ was calculated from Eq. (A4).
A further simplified Köhler equation (Eq. A21) was used to make VH3 model calculations. $\mu_{s}$ was taken as a primary variable to calculate $i_{s} . i_{s}, x_{s}, \rho_{w}, \rho_{\text {sol }}$, and $\sigma_{\text {sol }}$ were calculated as in VH1; $D_{\text {wet }}$ as in $\mathrm{VH} 2$; all parameters were inserted into Eq. (A21) to calculate $s$.

The VH4 model used Eq. (A22) to calculate $s . \mu_{s}$ was taken as a primary variable to calculate $i_{s} . i_{s}, x_{s}, \rho_{w}, \sigma_{w}$ were calculated as in VH1. $D_{\text {wet }}$ was calculated from Eq. (A4) which required the parameterization of $\rho_{\text {sol }}$. Because the Köhler equation used for VH4 was derived assuming $\rho_{\text {sol }}$ as $\rho_{w}$, the same approximation was also used to calculate $D_{\text {wet }}$.

For all VH model calculations, the maximum value of $s$ was determined by variation of $\mu_{s}$ (numerical minimum search for $-s$ with the "fminsearch" function, Matlab software). The critical supersaturation $S_{c}$ was calculated from the maximum of $s$ using Eq. (A2).

In sensitivity studies investigating the influence of simplifications and approximations, individual parameterizations were exchanged as detailed in Table 3, but the basic calculation procedure (VH1, VH2, $\mathrm{VH} 3, \mathrm{VH} 4)$ remained unchanged.

\section{A5 Effective hygroscopicity parameter (EH) models}

Petters and Kreidenweis (2007) defined a hygroscopicity parameter $\kappa$ that can be used to parameterize the composition dependent water activity of a solution droplet:

$a_{w}=\left(1+\kappa \frac{V_{s}}{V_{w}}\right)^{-1}$

with $V_{s}=n_{s} M_{s} / \rho_{s}$ and $V_{w}=n_{w} M_{w} / \rho_{w}$ being the volumes of the dry solute and of the water in the droplet, respectively. From comparison with Eq. (A18) follows:

$\kappa=i_{s} \frac{n_{s} V_{w}}{n_{w} V_{s}}=i_{s} \frac{v_{w}}{v_{s}}=i_{s} \frac{\rho_{s} M_{w}}{\rho_{w} M_{s}}$

with $v_{s}$ and $v_{w}$ being the molar volumes of the solute and of water, respectively. For the CCN activation of $\left(\mathrm{NH}_{4}\right)_{2} \mathrm{SO}_{4}$ and $\mathrm{NaCl}$, Petters and Kreidenweis (2007) proposed $\kappa$ values of 0.61 and 1.28 corresponding to $i_{s}=2.52$ and $i_{s}=1.91$, respectively. These $\kappa$ values were derived from the Aerosol Inorganics Model (AIM), fullfilling Eq. (A27) for $\left(\mathrm{NH}_{4}\right)_{2} \mathrm{SO}_{4}$ at $S_{c}=0.27 \%\left(D_{s}=67 \mathrm{~nm}\right)$ and for $\mathrm{NaCl}$ at $S_{c}=0.15 \%\left(D_{s}=80 \mathrm{~nm}\right)$.

Note that besides $\kappa$ also other effective hygroscopicity parameters have been proposed and can be used in analogy to describe the influence of soluble particle material on the $\mathrm{CCN}$ activation of aerosol particles. For example, Wex et al. (2007) have defined and used an "ion density" parameter $\rho_{\text {ion }}=\Phi_{s} v_{s} \rho_{s} / M_{s} \approx i_{s} \rho_{s} / M_{s}=\kappa \rho_{w} / M_{w}$. The above $\kappa$ values for $\left(\mathrm{NH}_{4}\right)_{2} \mathrm{SO}_{4}$ and $\mathrm{NaCl}$ are equivalent to $\rho_{\text {ion }}$ values of $3.38 \times 10^{4} \mathrm{~mol} \mathrm{~m}^{-3}$ and $7.08 \times 10^{4} \mathrm{~mol} \mathrm{~m}^{-3}$, respectively.

Assuming volume additivity $\left(V_{w}=V_{\text {wet }}-V_{s}\right.$, with the total volume of the solution droplet $V_{\text {wet }}$ ), and spherical shape of the dry solute particle and solution droplet (i.e., $D_{s}^{3}=6 V_{s} / \pi$ 
and $D_{\text {wet }}^{3}=6 V_{\text {wet }} / \pi$, respectively) Eq. (A27) can be rewritten as:

$a_{w}=\frac{D_{\mathrm{wet}}^{3}-D_{s}^{3}}{D_{\mathrm{wet}}^{3}-D_{s}^{3}(1-\kappa)}$

The full Köhler equation (Eq. A14) with $a_{w}$ taken from Eq. (A29) and $g_{s}$ from Eq. (A4) results in the following equation, which was used as the basis for EH1 Köhler model calculations:

$s=\frac{D_{\text {wet }}^{3}-D_{s}^{3}}{D_{\text {wet }}^{3}-D_{s}^{3}(1-\kappa)} \exp \left(\frac{4 \sigma_{\text {sol }} M_{w}}{R T \rho_{w} D_{\text {wet }}}\right)$

In EH1 Köhler model calculations $x_{s}$ was taken as the primary variable to calculate $D_{\text {wet }}$ from Eq. (A4) with $\rho_{\text {sol }}$ from Eq. (A9) and $\rho_{w}$ from Eq. (A11); $\sigma_{\text {sol }}$ was calculated from Eq. (A12) with $\sigma_{w}$ from Eq. (A13) and $c_{s}$ from Eq. (A6); and $s$ from Eq. (A30). The maximum value of $s$ (critical saturation ratio, $s_{c}$ ) was determined by the variation of $x_{s}$ (numerical minimum search for $-s$ with the "fminsearch" function, Matlab software), and via Eq. (A2) it was converted into the corresponding critical supersaturation $S_{c}$.

\section{A6 Analytical approximation (AA) model}

In all Köhler models that have been presented so far, the critical saturation $s_{c}$ was determined through numerical iteration by varying the primary variable (such as $\mu_{s}, x_{s}$, or $a_{w}$ ) for $s$ in the particular proposed equation until it reached a maximum. Assuming a concentration-independent van't Hoff factor or effective hygrosocopicity parameter, the iterative numerical solution can be approximated by a simplified analytical equation expressing $s_{c}$ as a function of dry solute particle mass equivalent diameter, $D_{s}$ (Seinfeld and Pandis, 1998; Petters and Kreidenweis, 2007):

$s_{c}=\exp \left(\sqrt{\frac{4 A^{3}}{27 B}}\right)=\exp \left(\sqrt{\frac{4 A^{3} M_{s} \rho_{w}}{27 i_{s} M_{w} \rho_{s} D_{s}^{3}}}\right)$

$s_{c}=\exp \left(\sqrt{\frac{4 A^{3}}{27 \kappa D_{s}^{3}}}\right)$

In the AA model calculations, the widely used approximation $A \approx\left(0.66 \times 10^{-6} \mathrm{Km}\right) / T$ was inserted for the Kelvin term parameter $A$ as defined in Eq. (A23) (Seinfeld and Pandis, 1998) and different values of $i_{s}$ and $\kappa$ were tested $\left(i_{s}=2.2\right.$ or 3 and $\kappa=0.61$ for ammonium sulfate; $i_{s}=2$ and $\kappa=1.28$ for sodium chloride).

A comparison and discussion of critical supersaturations calculated with the different AP, OS, VH, EH and AA models specified above is given in Sect. 3.7. For CCNC calibration, the VH4 model has been used in this study unless mentioned otherwise.

\section{Appendix B}

\section{Notation (frequently used symbols)}

\begin{tabular}{|c|c|c|}
\hline Symbol & Unit & Quantity \\
\hline$a_{w}$ & & water activity \\
\hline$C$ & & slip correction factor \\
\hline$c_{s}$ & $\mathrm{~mol} \mathrm{~L}^{-1}$ & molarity of solute \\
\hline$D$ & $\mathrm{~m}$ & dry particle diameter \\
\hline$D_{a}$ & $\mathrm{~m}$ & $\begin{array}{l}\text { mid point diameter of } \mathrm{CCN} \text { effi- } \\
\text { ciency spectrum (fit parameter) }\end{array}$ \\
\hline$D_{B}$ & $\mathrm{~m}$ & mobility equivalent diameter \\
\hline$D_{c}$ & $\mathrm{~m}$ & critical dry particle diameter \\
\hline$D_{m}$ & $\mathrm{~m}$ & mass equivalent diameter \\
\hline$D_{s}$ & $\mathrm{~m}$ & $\begin{array}{l}\text { mass equivalent diameter of dry so- } \\
\text { lute particle }\end{array}$ \\
\hline$D_{\text {wet }}$ & $\mathrm{m}$ & droplet diameter \\
\hline$D_{\text {wet }, c}$ & $\mathrm{~m}$ & critical droplet diameter \\
\hline$g_{s}$ & & particle growth factor \\
\hline$i_{s}$ & & van't Hoff factor of solute \\
\hline$m_{s}$ & $\mathrm{~kg}$ & mass of dry solute \\
\hline$M_{S}$ & $\mathrm{~kg} \mathrm{~mol}^{-1}$ & molar mass of solute \\
\hline$m_{w}$ & $\mathrm{~kg}$ & mass of water \\
\hline$M_{w}$ & $\mathrm{~kg} \mathrm{~mol}^{-1}$ & molar mass of water \\
\hline$N_{\mathrm{CCN}}$ & $\mathrm{cm}^{-3}$ & number concentration of $\mathrm{CCN}$ \\
\hline$N_{\mathrm{CN}}$ & $\mathrm{cm}^{-3}$ & number concentration of $\mathrm{CN}$ \\
\hline$n_{s}$ & mol & number of moles of solute \\
\hline$n_{w}$ & mol & number of moles of water \\
\hline$p$ & $\mathrm{~Pa}$ & pressure \\
\hline$Q$ & $\mathrm{~L} \min ^{-1}$ & total flow rate of $\mathrm{CCNC}$ \\
\hline$R$ & $\mathrm{~J} \mathrm{~K}^{-1} \mathrm{~mol}^{-1}$ & universal gas constant \\
\hline RH & $\%$ & relative humidity \\
\hline$R_{T}$ & $\mathrm{~K} \mathrm{~W}^{-1}$ & thermal resistance of $\mathrm{CCNC}$ \\
\hline$s$ & & water vapor saturation ratio \\
\hline$s_{c}$ & & critical water vapor saturation ratio \\
\hline$S$ & $\%$ & water vapor supersaturation \\
\hline$S_{c}$ & $\%$ & critical water vapor supersaturation \\
\hline$S_{\text {eff }}$ & $\%$ & $\begin{array}{l}\text { effective supersaturation of water } \\
\text { vapor in CCNC }\end{array}$ \\
\hline$T$ & $\mathrm{~K}$ & absolute temperature \\
\hline$T_{1}$ & $\mathrm{~K}$ & CCNC column top temperature \\
\hline$T_{2}$ & $\mathrm{~K}$ & CCNC column middle temperature \\
\hline$T_{3}$ & $\mathrm{~K}$ & CCNC column bottom temperature \\
\hline$x_{s}$ & & $\begin{array}{l}\text { mass fraction of solute in the } \\
\text { droplet }\end{array}$ \\
\hline$\Phi_{s}$ & & $\begin{array}{l}\text { molal or practical osmotic coeffi- } \\
\text { cient of solute }\end{array}$ \\
\hline$\mu_{s}$ & $\operatorname{mol~kg}{ }^{-1}$ & molality of solute \\
\hline$\Delta T$ & $\mathrm{~K}$ & $\begin{array}{l}\text { temperature difference at the outer } \\
\text { wall of the CCNC column }\end{array}$ \\
\hline$\Delta T^{*}$ & $\mathrm{~K}$ & flow model temperature difference \\
\hline$\Delta T_{0}$ & $\mathrm{~K}$ & temperature difference offset \\
\hline$\Delta T_{\text {inner }}$ & $\mathrm{K}$ & $\begin{array}{l}\text { temperature difference inside the } \\
\text { CCNC column }\end{array}$ \\
\hline$\eta$ & & thermal efficiency of the CCNC \\
\hline$v_{s}$ & & $\begin{array}{l}\text { stoichiometric dissociation number } \\
\text { of solute }\end{array}$ \\
\hline$\rho_{s}$ & $\mathrm{~kg} \mathrm{~m}^{-3}$ & density of dry solute \\
\hline$\rho_{\text {sol }}$ & $\mathrm{kg} \mathrm{m}^{-3}$ & density of solution droplet \\
\hline$\rho_{w}$ & $\mathrm{~kg} \mathrm{~m}^{-3}$ & density of pure water \\
\hline$\sigma_{\text {sol }}$ & $\mathrm{J} \mathrm{m}^{-2}$ & surface tension of solution droplet \\
\hline$\sigma_{w}$ & $\mathrm{~J} \mathrm{~m}^{-2}$ & surface tension of pure water \\
\hline$\chi$ & & dynamic shape factor \\
\hline$\lambda$ & $\mathrm{m}$ & mean free path \\
\hline
\end{tabular}


Acknowledgements. This work was funded by the Max Planck Society (MPG). The authors gratefully acknowledge support by the organizers, teams, hosts, and funding organizations of the measurement campaigns during which the reported calibration experiments have been performed: Beijing and Guangzhou: CAREBEIJING 2006, PRIDE-PRD 2006, PKU; Hohenpeißenberg: ANTISTORM, DWD; Mt. Jungfraujoch: CLACE-5 and -6, HFSJG, SFB-TROPEIS; Leipzig: LExNo, IfT, ACCENT. Thanks to T. W. Andreae for help in manuscript preparation, and to G. Biskos, C. Chan, S. Clegg, S. Kreidenweis, M. Kuwata, S. Martin, T. Mentel, D. Topping, A. Wexler, the three anonymous referees, and the editor $\mathrm{A}$. Nenes for helpful comments and discussion. E. Mikhailov acknowledges support by the Russian Foundation for Basic Research (project no. 05-05-64756-a).

Edited by: A. Nenes

\section{References}

Andreae, M. O., Hegg, D., Feichter, J., Kloster, S., Levin, Z., Liousse, C., Radke, L., and Stier, P.: Sources and nature of atmospheric aerosols, in: Scientific assessment of the effects of aerosols on precipitation, edited by: Levin, Z. and Cotton, W., World Meteorological Organization, 2007.

Andreae, M. O., Jones, C. D., and Cox, P. M.: Strong present-day aerosol cooling implies a hot future, Nature, 435, 1187-1190, 2005.

Andreae, M. O., Rosenfeld, D., Artaxo, P., Costa, A. A., Frank, G. P., Longo, K. M., and Silva-Dias, M. A. F.: Smoking rain clouds over the Amazon, Science, 303, 1337-1342, 2004.

Bilde, M. and Svenningsson, B.: CCN activation of slightly soluble organics: the importance of small amounts of inorganic salt and particle phase, Tellus B, 56, 128-134, 2004.

Biskos, G., Paulsen,D., Russell, L. M., Buseck, P. R., and Martin, S. T.: Prompt deliquescence and efflorescence of aerosol nanoparticles, Atmos. Chem. Phys., 6, 4633-4642, 2006 a.

Biskos, G., Russell, L. M., Buseck, P. R., and Martin, S. T.: Nanosize effect on the hygroscopic growth factor of aerosol particles, Geophys. Res. Lett., 33, L07801, doi:10.1029/2005GL025199, 2006b.

Brechtel, F. J. and Kreidenweis, S. M.: Predicting Particle Critical Supersaturation from Hygroscopic Growth Measurements in the Humidified TDMA. Part I: Theory and Sensitivity Studies, J. Atmos. Sci., 57, 1854-1871, 2000.

Broekhuizen, K., Pradeep Kumar, P., and Abbatt, J. P. D.: Partially soluble organics as cloud condensation nuclei: Role of trace soluble and surface active species, Geophys. Res. Lett., 31, L01107, doi:10.1029/2003GL018203, 2004.

Broekhuizen, K., Chang, R. Y.-W., Leaitch, W. R., Li, S.-M., and Abbatt, J. P. D.: Closure between measured and modeled cloud condensation nuclei (CCN) using size-resolved aerosol compositions in downtown Toronto, Atmos. Chem. Phys., 6, 2513-2524, 2006, http://www.atmos-chem-phys.net/6/2513/2006/.

Chan, M. N. and Chan, C. K.: Mass transfer effects in hygroscopic measurements of aerosol particles, Atmos. Chem. Phys., 5, 2703-2712, 2005, http://www.atmos-chem-phys.net/5/2703/2005/.
Charlson, R. J., Seinfeld, J. H., Nenes, A., Kulmala, M., Laaksonen, A., and Facchini, M. C.: Reshaping the theory of cloud formation, Science, 292, 2025-2026, 2001.

Chen, J.-P.: Theory of Deliquescence and Modified Köhler Curves, J. Atmos. Sci., 51, 3505-3516, 1994.

Chuang, P. Y., Collins, D. R., Pawlowska, H., Snider, J. R., Jonsson, H. H., Brenguier, J. L., Flagan, R. C., and Seinfeld, J. H.: CCN measurements during ACE-2 and their relationship to cloud microphysical properties, Tellus B, 52, 843-867, 2000.

Clegg, S. L., Brimblecombe, P., and Wexler, A. S.: A thermodynamic model of the system $\mathrm{H}^{+}-\mathrm{NH}_{4}^{+}-\mathrm{SO}_{4}^{2-}-\mathrm{NO}^{3-}-\mathrm{H}_{2} \mathrm{O}$ at tropospheric temperatures, J. Phys. Chem. A, 102, 2137-2154, 1998a.

Clegg, S. L., Brimblecombe, P., and Wexler, A. S.: A thermodynamic model of the system $\mathrm{H}^{+}-\mathrm{NH}_{4}^{+}-\mathrm{Na}^{+}-\mathrm{SO}_{4}^{2-}-\mathrm{NO}^{3-}$ $-\mathrm{Cl}^{-}-\mathrm{H}_{2} \mathrm{O}$ at $298.15 \mathrm{~K}$, J. Phys. Chem. A, 102, 2155-2171, 1998 b.

Clegg, S. L. and Wexler, A. S.: Interactive comment on "Calibration and measurement uncertainties of a continuous-flow cloud condensation nuclei counter (DMT-CCNC): CCN activation of ammonium sulfate and sodium chloride aerosol particles in theory and experiment" by D. Rose et al., Atmos. Chem. Phys. Discuss., 7, S4180-S4183, 2007.

DeCarlo, P. F., Slowik, J. G., Worsnop, D. R., Davidovits, P., and Jimenez, J. L.: Particle Morphology and Density Characterization by Combined Mobility and Aerodynamic Diameter Measurements. Part 1: Theory, Aerosol Sci. Technol., 38, 11851205, 2004.

Delene, D. J. and Deshler, T.: Calibration of a photometric cloud condensation nucleus counter designed for deployment on a balloon package, J. Atmos. Oceanic Technol., 17, 459-467, 2000.

Delene, D. J. and Deshler, T.: Vertical profiles of cloud condensation nuclei above Wyoming, J. Geophys. Res., 106, 12579 $12588,2001$.

Dinar, E., Taraniuk, I., Graber, E. R., Katsman, S., Moise, T., Anttila, T., Mentel, T. F., and Rudich, Y.: Cloud Condensation Nuclei properties of model and atmospheric HULIS, Atmos. Chem. Phys., 6, 2465-2482, 2006, http://www.atmos-chem-phys.net/6/2465/2006/.

Dusek, U., Frank, G. P., Hildebrandt, L., Curtius, J., Schneider, J., Walter, S., Chand, D., Drewnick, F., Hings, S., Jung, D., Borrmann, S., and Andreae, M. O.: Size Matters More Than Chemistry for Cloud-Nucleating Ability of Aerosol Particles, Science, 312, 1375-1378, 2006.

Engelhart, G. J., Asa-Awuku, A., Nenes, A., and Pandis, S. N.: $\mathrm{CCN}$ activity and droplet growth kinetics of fresh and aged monoterpene secondary organic aerosol, Atmos. Chem. Phys. Discuss., 8, 95-135, 2008, http://www.atmos-chem-phys-discuss.net/8/95/2008/.

Ervens, B., Cubison, M., Andrews, E., Feingold, G., Ogren, J. A., Jimenez, J. L., DeCarlo, P., and Nenes, A.: Prediction of cloud condensation nucleus number concentration using measurements of aerosol size distributions and composition and light scattering enhancement due to humidity, J. Geophys. Res., 112, D10S32, doi:10.1029/2006JD007426, 2007.

Frank, G. P., Dusek, U., and Andreae, M. O.: Technical note: A method for measuring size-resolved $\mathrm{CCN}$ in the atmosphere, Atmos. Chem. Phys. Discuss., 6, 4879-4895, 2006, http://www.atmos-chem-phys-discuss.net/6/4879/2006/. 
Frank, G. P., Dusek, U., and Andreae, M. O.: Technical Note: Characterization of a static thermal-gradient $\mathrm{CCN}$ counter, Atmos. Chem. Phys., 7, 3071-3080, 2007, http://www.atmos-chem-phys.net/7/3071/2007/.

Gerber, H. E., Hoppel, W. A., and Wojciechowski, T. A.: Experimental verification of the theoretical relationship between size and critical supersaturation of salt nuclei, J. Atmos. Sci., 34, 1836-1841, 1977.

Giebl, H., Berner, A., Reischl, G., Puxbaum, H., Kasper-Giebl, A., and Hitzenberger, R.: CCN activation of oxalic and malonic acid test aerosols with the University of Vienna cloud condensation nuclei counter, J. Aerosol Sci., 33, 1623-1634, 2002.

Gras, J. L.: CN, CCN and particle size in Southern Ocean air at Cape Grim, Atmos. Res., 35, 233-251, 1995.

Gysel, M., Weingartner, E., and Baltensperger, U.: Hygroscopicity of Aerosol Particles at Low Temperatures. 2. Theoretical and Experimental Hygroscopic Properties of Laboratory Generated Aerosols, Environ. Sci. Technol., 36, 63-68, 2002.

Hänel, G.: The properties of atmospheric aerosol particles as functions of the relative humidity at thermodynamic equilibrium with the surrounding moist air, Adv. Geophys., 19, 73-188, 1976.

Henning, S., Rosenorn, T., D’ Anna, B., Gola, A. A., Svenningsson, B., and Bilde, M.: Cloud droplet activation and surface tension of mixtures of slightly soluble organics and inorganic salt, Atmos. Chem. Phys., 5, 575-582, 2005,

http://www.atmos-chem-phys.net/5/575/2005/.

Hudson, J. G.: An Instantaneous CCN Spectrometer, J. Atmos. Oceanic Technol., 6, 1055-1065, 1989.

Hudson, J. G.: Cloud Condensation Nuclei, J. Appl. Meteorol., 32, 596-607, 1993.

Hudson, J. G. and Xie, Y.: Vertical distributions of cloud condensation nuclei spectra over the summertime northeast Pacific and Atlantic Oceans, J. Geophys. Res., 104, 30 219-30 229, 1999.

Hudson, J. G. and Yum, S. S.: Cloud condensation nuclei spectra and polluted and clean clouds over the Indian Ocean, J. Geophys. Res., 107, 8022, doi:10.1029/2001JD000829, 2002.

IAPSAG: International aerosol precipitation science assessment group (IAPSAG): Aerosol pollution impact on precipitation: a scientific review, 2007.

IPCC: Climate Change 2007: The Physical Science Basis: Summary for Policymakers. Contribution of Working Group I to the Fourth Assessment Report of the Intergovernmental Panel on Climate Change, 2007.

Khain, A., Rosenfeld, D., and Pokrovsky, A.: Aerosol impact on the dynamics and microphysics of deep convective clouds, Q. J. Roy. Meteorol. Soc., 131, 2639-2663, 2005.

Knutson, E. O. and Whitby, K. T.: Aerosol classification by electric mobility: apparatus, theory, and applications, J. Aerosol Sci., 6, 443-451, 1975.

Koehler, K. A., Kreidenweis, S. M., DeMott, P. J., Prenni, A. J., Carrico, C. M., Ervens, B., and Feingold, G.: Water activity and activation diameters from hygroscopicity data-Part II: Application to organic species, Atmos. Chem. Phys., 6, 795-809, 2006, http://www.atmos-chem-phys.net/6/795/2006/.

Köhler, H.: The nucleus in and the growth of hygroscopic droplets: Trans. Faraday Soc., 32, 1152-1161, 1936.

Krämer, L., Pöschl, U., and Niessner, R.: Microstructural rearrangement of sodium chloride condensation aerosol particles on interaction with water vapor, J. Aerosol Sci., 31, 673-685, 2000.
Kreidenweis, S. M., Koehler, K., DeMott, P. J., Prenni, A. J., Carrico, C., and Ervens, B.: Water activity and activation diameters from hygroscopicity data-Part I: Theory and application to inorganic salts, Atmos. Chem. Phys., 5, 1357-1370, 2005, http://www.atmos-chem-phys.net/5/1357/2005/.

Kuwata, M., Kondo, Y., Miyazaki, Y., Komazaki, Y., Kim, J. H., Yum, S. S., Tanimoto, H., and Matsueda, H.: Cloud condensation nuclei activity at Jeju Island, Korea in spring 2005, Atmos. Chem. Phys. Discuss., 7, 15 805-15 851, 2007a.

Kuwata, M., Kondo, Y., Mochida, M., Takegawa, N., and Kawamura, K.: Dependence of CCN activity of less volatile particles on the amount of coating observed in Tokyo, J. Geophys. Res., 112, D11207, doi:10.1029/2006JD007758, 2007b.

Lance, S., Medina, J., Smith, J. N., and Nenes, A.: Mapping the Operation of the DMT Continuous Flow CCN Counter, Aerosol Sci. Technol., 40, 242-254, 2006.

Lohmann, U. and Feichter, J.: Global indirect aerosol effects: a review: Atmos. Chem. Phys., 5, 715-737, 2005, http://www.atmos-chem-phys.net/5/715/2005/.

Low, R. D. H.: A theoretical study of nineteen condensation nuclei, Journal de Recherches Atmospheriques, 4, 65-78, 1969.

McDonald, J. E.: Erroneous cloud-physics applications of Raoult Law., J. Meteorol., 10, 68-78, 1953.

McFiggans, G., Artaxo, P., Baltensperger, U., Coe, H., Facchini, M. C., Feingold, G., Fuzzi, S., Gysel, M., Laaksonen, A., Lohmann, U., Mentel, T. F., Murphy, D. M., O’Dowd, C. D., Snider, J. R., and Weingartner, E.: The effect of physical and chemical aerosol properties on warm cloud droplet activation, Atmos. Chem. Phys., 6, 2593-2649, 2006,

http://www.atmos-chem-phys.net/6/2593/2006/.

Mikhailov, E., Vlasenko, S., Niessner, R., and Pöschl, U.: Interaction of aerosol particles composed of protein and salts with water vapor: hygroscopic growth and microstructural rearrangement, Atmos. Chem. Phys., 4, 323-350, 2004, http://www.atmos-chem-phys.net/4/323/2004/.

Mokbel, I., Ye, S., Jose, J., and Xans, P.: Study of non ideality of various aqueous sodium chloride solutions by vapor pressures measurements and correlation of experimental results by Pitzer's method, J. Chim. Phys., 94, 122-137, 1997.

Padró, L. T., Asa-Awuku, A., Morrison, R., and Nenes, A.: Inferring thermodynamic properties from $\mathrm{CCN}$ activation experiments: single-component and binary aerosols, Atmos. Chem. Phys., 7, 5263-5274, 2007, http://www.atmos-chem-phys.net/7/5263/2007/.

Petters, M. D. and Kreidenweis, S. M.: A single parameter representation of hygroscopic growth and cloud condensation nucleus activity, Atmos. Chem. Phys., 7, 1961-1971, 2007, http://www.atmos-chem-phys.net/7/1961/2007/.

Petters, M. D., Prenni, A. J., Kreidenweis, S. M., and DeMott, P. J.: On Measuring the Critical Diameter of Cloud Condensation Nuclei Using Mobility Selected Aerosol, Aerosol Sci. Technol., 41, 907-913, doi:10.1080/02786820701557214, 2007.

Pitzer, K. S. and Mayorga, G.: Thermodynamics of electrolytes. II. Activity and osmotic coefficients for strong electrolytes with one or both ions univalent, J. Phys. Chem., 77, 2300-2308, 1973.

Pradeep Kumar, P., Broekhuizen, K., and Abbatt, J. P. D.: Organic acids as cloud condensation nuclei: Laboratory studies of highly soluble and insoluble species, Atmos. Chem. Phys., 3, 509-520, 2003, 
http://www.atmos-chem-phys.net/3/509/2003/.

Pruppacher, H. R. and Klett, J. D.: Microphysics of clouds and precipitation, Dordrecht, Kluwer Academic Publishers, 1997.

Raymond, T. M. and Pandis, S. N.: Formation of cloud droplets by multicomponent organic particles, J. Geophys. Res., 108, 4469, doi:10.1029/2003JD003503, 2003.

Reade, L., Jennings, S. G., and McSweney, G.: Cloud condensation nuclei measurements at Mace Head, Ireland, over the period 1994-2002, Atmos. Res., 82, 610-621, 2006.

Rissman, T. A., Varutbangkul, V., Surratt, J. D., Topping, D. O., McFiggans, G., Flagan, R. C., and Seinfeld, J. H.: Cloud condensation nucleus $(\mathrm{CCN})$ behavior of organic aerosol particles generated by atomization of water and methanol solutions, Atmos. Chem. Phys., 7, 2949-2971, 2007,

http://www.atmos-chem-phys.net/7/2949/2007/.

Roberts, G., Mauger, G., Hadley, O., and Ramanathan, V.: North American and Asian aerosols over the eastern Pacific Ocean and their role in regulating cloud condensation nuclei, J. Geophys. Res., 111, D13205, doi:10.1029/2005JD006661, 2006.

Roberts, G. C. and Nenes, A.: A Continuous-Flow Streamwise Thermal-Gradient CCN Chamber for Atmospheric Measurements, Aerosol Sci. Technol., 39, 206-221, 2005.

Robinson, R. A. and Stokes, R. H.: Electrolyte Solutions, (revised), London: Butterworth, 1959.

Rose, D., Frank, G. P., Dusek, U., Gunthe, S. S., Andreae, M. O., and Pöschl, U.: Interactive comment on "Calibration and measurement uncertainties of a continuous-flow cloud condensation nuclei counter (DMT-CCNC): CCN activation of ammonium sulfate and sodium chloride aerosol particles in theory and experiment” by D. Rose et al., Atmos. Chem. Phys. Discuss., 7, S4127-S4129, 2007.

Rosenfeld, D. and Givati, A.: Evidence of orographic precipitation suppression by air pollution-induced aerosols in the western United States, J. Appl. Meteorol. Climatol., 45, 893-911, 2006.

Scheibel, H. G. and Porstendörfer, J.: Generation of monodisperse $\mathrm{Ag}$-and $\mathrm{NaCl}$-aerosols with particle diameters between 2 and 300 nm, J. Aerosol Sci., 14, 113-126, 1983.

Shilling, J. E., King, S. M., Mochida, M., Worsnop, D. R., and Martin, S. T.: Mass Spectral Evidence that Small Changes in Composition Caused by Oxidative Aging Processes Alter Aerosol CCN Properties, J. Phys. Chem. A, 111, 3358-3368, 2007.

Segal, Y. and Khain, A.: Dependence of droplet concentration on aerosol conditions in different cloud types: Application to droplet concentration parameterization of aerosol conditions, J. Geophys. Res., 111, D15204, doi:10.1029/2005JD006561, 2006.

Segal, Y., Khain, A., Pinsky, M., and Sterkin, A.: Sensitivity of raindrop formation in ascending cloud parcels to cloud condensation nuclei and thermodynamic conditions, Q. J. Roy. Meteorol. Soc., 130, 561-581, 2004.
Seinfeld, J. H. and Pandis, S. N.: Atmospheric Chemistry and Physics: From Air Pollution to Climate Change, New York: John Wiley \& Sons, Inc., 1998.

Snider, J. R., Guibert, S., Brenguier, J.-L., and Putaud, J.-P.: Aerosol activation in marine stratocumulus clouds: 2. Köhler and parcel theory closure studies, J. Geophys. Res., 108, 8629, doi:10.1029/2002JD002692, 2003.

Snider, J. R., Petters, M. D., Wechsler, P., and Liu, P. S. K.: Supersaturation in the Wyoming CCN Instrument, J. Atmos. Oceanic Technol., 23, 1323-1339, 2006.

Tang, I. N.: Chemical and size effects of hygroscopic aerosols on light scattering coefficients, J. Geophys. Res., 101, 19245$19250,1996$.

Tang, I. N. and Munkelwitz, H. R.: Water activities, densities, and refractive indices of aqueous sulfates and sodium nitrate droplets of atmospheric importance, J. Geophys. Res., 99, 18 801-18 808, 1994.

Weast, R. C. and Astle, M. J.: CRC Handbook of Chemistry and Physics, 63rd. Florida: CRC Press Inc., 1982.

Wex, H., Kiselev, A., Stratmann, F., Zoboki, J., and Brechtel, F.: Measured and modeled equilibrium sizes of $\mathrm{NaCl}$ and (NH4)2SO4 particles at relative humidities up to $99.1 \%$, J. Geophys. Res., 110, D21212, doi:10.1029/2004JD005507, 2005.

Wex, H., Kiselev, A., Ziese, M., and Stratmann, F.: Calibration of LACIS as a CCN detector and its use in measuring activation and hygroscopic growth of atmospheric aerosol particles, Atmos. Chem. Phys., 6, 4519-4527, 2006, http://www.atmos-chem-phys.net/6/4519/2006/.

Wiedensohler, A.: An approximation of the bipolar charge distribution for particles in the submicron size range, J. Aerosol Sci., 19, 387-389, 1988.

Willeke, K. and Baron, P. A.: Aerosol Measurement: Principles, Techniques, and Applications. (2nd ed.). New York: John Wiley \& Sons, Inc., 2001.

Young, K. C. and Warren, A. J.: A reexamination of the derivation of the equilibrium supersaturation curve for soluble particles, J. Atmos. Sci., 49, 1138-1143, 1992.

Yum, S. S., Roberts, G., Kim, J. H., Song, K., and Kim, D.: Submicron aerosol size distributions and cloud condensation nuclei concentrations measured at Gosan, Korea, during the Atmospheric Brown Clouds-East Asian Regional Experiment 2005, J. Geophys. Res., 112, D22S32, doi:10.1029/2006JD008212, 2007. 